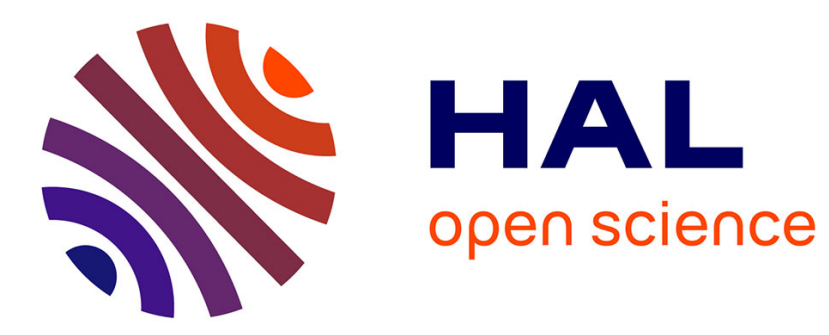

\title{
Tetrathiafulvalene-Based Magnets of Lanthanides
}

Olivier Cador, Fabrice Pointillart

\section{To cite this version:}

Olivier Cador, Fabrice Pointillart. Tetrathiafulvalene-Based Magnets of Lanthanides. Topics in Organometallic Chemistry, Springer, 2018. hal-01940620

\section{HAL Id: hal-01940620 \\ https://hal-univ-rennes1.archives-ouvertes.fr/hal-01940620}

Submitted on 14 Dec 2018

HAL is a multi-disciplinary open access archive for the deposit and dissemination of scientific research documents, whether they are published or not. The documents may come from teaching and research institutions in France or abroad, or from public or private research centers.
L'archive ouverte pluridisciplinaire HAL, est destinée au dépôt et à la diffusion de documents scientifiques de niveau recherche, publiés ou non, émanant des établissements d'enseignement et de recherche français ou étrangers, des laboratoires publics ou privés. 


\section{Introduction}

Magnets have been discovered about four millenniums ago in ancient Greece. Nowadays, in 2015, permanent magnets market is valued to 15 billion $€$ and is expected to grow according to the demands for medical and industrial devices. In this market, the segment occupied by the badly named rare-earth ${ }^{1}$-based magnets continues to expand owing to superior properties (such as saturation magnetization).

In the 1990s, a new class of magnets emerged in the scientific community with the discovery of the single-molecule magnets (SMMs) [1]. In these magnets, the magnetic memory is stored by the magnetic moment of a single molecule constituted of 12 manganese ions. This scientific finding reduced the size of a storage unit (byte) to nanometer. At the same time, the storage capacity of hard disks based on molecules would increase drastically. The drawback is the operating temperature range, below liquid helium $\left(-269^{\circ} \mathrm{C}\right)$. In the last three decades, the quest for better SMMs never really stopped. In 2003, Ishikawa et al. [2] discovered that a single lanthanide ion $\left(\mathrm{Ln}=\mathrm{Tb}^{\mathrm{III}}\right)$ embedded in a double-decker complex behaved as a SMM. To date, the lanthanide series is the most productive SMMs line in Mendeleev's periodic table with a recent tremendous record of closure of the magnetic hysteresis loop at $60 \mathrm{~K}[3,4]$, close to liquid nitrogen.

Tetrathiafulvalene (TTF) and its analogues are well known in the field of molec-

ular materials to produce organic metals, semiconductors, and superconductors $[5,6]$. The functionalization of the electron donor TTF core by an acceptor moiety contributed to the development of functional materials such as switches, sensors, photovoltaic cells, and nonlinear optical systems [7-9]. It was then logical to adapt the acceptor moiety to coordinate transition metals for (1) elaboration of multifunctional materials with both paramagnetism and electrical conductivity $[10,11]$ and (2) the synthesis of polynuclear transition metal complexes exhibiting SMM properties embedded in a conducting material [12-16]. One must admit that all tentative proposals were not very successful except Oshio's work [17] which

shows SMM behavior but without conductiyity
The first TTF-Ln system was reported by Faulkner et al. [18] with the assembly in solution of tetrathiafulvalene carboxylic acid and ytterbium. In 2003 [19], the first structurally characterized TTF-Ln system in the solid state was reported. There was no chemical bond between the lanthanide ion and the TTF moiety, so the chemical approach is the so-called through space. We have published almost 10 years ago the first isolated TTF-Ln coordination complex [20] based on the spin-only Gd(III) ion, which, of course, does not behave as a SMM. Since 2009, several groups [21-24], including us [25], have paid much attention to TTF-Ln systems with the objectives to combine conductivity (electrical transport), magnetism (magnetic memory), and luminescence (light emitter) in a single chemical object. In this frame, the TTF moiety turns out to be a powerful sensitizer of the NIR luminescence of

${ }^{1}$ Most of the rare earths are not rare: cerium is more abundant than copper on earth, and thulium (the most rare) is more abundant than silver. 
lanthanides [26]. Nevertheless and despite colossal efforts of the scientific commu- 69 nity, electrical conductivity has never been observed in TTF-Ln systems. One could 70 say that the necessary oxidation (partial) of the TTF moiety to promote electronic 71 transport does not preserve the chemical integrity of the complex (dissociation) 72 except when both TTF core and coordinating moiety are not fused [27]. Despite 73 several attempts, there is no SMM based on TTF and strongly anisotropic 3-D 74 transition metals such as $\mathrm{Co}(\mathrm{II})$ and $\mathrm{Ni}(\mathrm{II})$ [12, 13, 28, 29]. But TTF performed in 75 the field of SMMs with plethora of mononuclear and polynuclear complexes which 76 possess a magnetic memory in the absence and, in less extent, in the presence of an 77 external constant magnetic field. Since highly anisotropic magnetic moments are 78 necessary, Dy(III) and $\mathrm{Tb}(\mathrm{III})$ are the ideal candidates [30-37]. These two ions 79 represent almost 99\% of reported Ln-based SMMs [38] with a preponderant role 80 played by Dy(III)-based systems.

\section{Preamble}

Naturally, researchers have at first focused their attention on the synthesis of mono- 83 nuclear TTF-Dy complexes. Like most of the time, the first attempt was not very 84 successful [39]. The reaction of two equivalents of tetrathiafulvalene-amido-2-pyri- 85 dine- $N$-oxide with $\left[\mathrm{Dy}(\mathrm{hfac})_{3}\right] \cdot 2 \mathrm{H}_{2} \mathrm{O}$ ( $\mathrm{hfac}^{-}: 1,1,1,5,5,5$-hexafluoroacetylacetonate 86 anion) precursor produced mononuclear species in which Dy(III) is surrounded by 87 eight oxygen atoms: two from pyridine- $N$-oxide moieties and six from three 88 bidentates $\mathrm{hfac}^{-}$. This fully oxygenated environment adopts a coordination polyhe- 89 dron close to square antiprism $(\mathrm{SAP}) \mathrm{D}_{4 \mathrm{~d}}$ with $\mathrm{CShM}=0.528$ [40]. The material does 90 not show any out-of-phase component of the AC susceptibility in zero external dc 91 field down to $2 \mathrm{~K}$ below oscillating field frequencies of $1 \mathrm{kHz}$. In other words, it is not 92 a magnet. Probably, the charge distribution around the Dy(III) center does not match 93 the axiality required by the simple but chemically implementable precepts exposed by 94 Rinehart et al. [41]. Performant magnets are obtained when the largest $M_{J}$ states are 95 stabilized for a given multiplet ground state $\left(M_{J}= \pm 15 / 2\right.$ for Dy(III)). The analysis of 96 the electron density distribution provides a simple tool to anticipate what might be the 97 ground state in a given environment [42]. The charge density distribution of the Ising 98 component (the largest $M_{J}$ values) of the multiplet ground state of the oblate Dy(III) is 99 represented on Fig. 1. The electrons are principally located in a plane (xy), so the 100 disposition of negatively charged ligands in the $z$ direction will stabilize this Kramers 101 state. It is the opposite for the prolate $\mathrm{Yb}$ (III) for which the negative charges must lie in 102 the $x y$ plane. This textbook analysis guided the synthesis of the most efficient SMM 103 reported so far [3, 4]. Additionally, advanced quantum calculations have demon- 104 strated that such approach might provide high-temperature SMMs (if chemically 105 accessible) [43, 44]. 
Fig. 1 Angular dependences of the total $4 f$ charge density for largest $M_{J}$ states of the multiplet ground state for Dy(III) and $\mathrm{Yb}(\mathrm{III})$
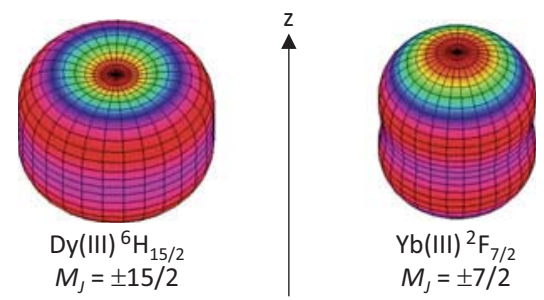

\section{Mononuclear TTF-Dy(III) SMMs: The $\mathbf{N}_{2} \mathbf{O}_{6}$ Saga}

108 We have sought, at first, for neutral complexes to crystallize with bidentate 109 TTF-based ligands in order to (1) stabilize the complexes and (2) minimize the 110 degrees of freedom of the coordination sphere. The use of three negatively charged 111 acetylacetonate $(-1)$ ancillary ligands counterbalances the charge +3 of the lantha112 nide ions and insures complex neutrality. To complete the coordination sphere, 113 TTF-based ligands with nitrogen-coordinating sites have been designed to 114 desymmetrize the ligand field (preamble). The first two complexes synthesized with 115 this approach are $\left[\mathrm{Dy}(\mathrm{hfac})_{3} \mathbf{L}^{\mathbf{1}}\right]$ and $\left[\mathrm{Dy}(\mathrm{hfac})_{3} \mathbf{L}^{\mathbf{2}}\right]$ (with $\mathbf{L}^{\mathbf{1}}=2$ - $\{4,5$-[4,5-bis 116 (propylthio)-tetrathiafulvalenyl]-1H-benzimidazol-2-yl $\}$ pyridine and $\mathbf{L}^{\mathbf{2}}=2$ - $\{1$ 117 methylpyridyl-4,5-[4,5-bis(propylthio)tetra-thiafulvalenyl]-1H-benzimidazol-2-yl 118 pyridine) [45] (Fig. 2). Except the obvious chemical difference at N3 (alkylation), the 119 analysis of the crystallographic structure revealed the presence of intermolecular 120 hydrogen bond at N3 site in $\left[\mathrm{Dy}(\mathrm{hfac})_{3} \mathbf{L}^{\mathbf{1}}\right]$. Such intermolecular connection does 121 not exist in $\left[\mathrm{Dy}(\mathrm{hfac})_{3} \mathbf{L}^{2}\right]$, and it has a dramatic consequence on the coordination 122 polyhedra. Indeed, the polyhedron is strongly distorted in $\left[\mathrm{Dy}(\mathrm{hfac})_{3} \mathbf{L}^{\mathbf{1}}\right]$ with respect 123 to the one in $\left[\mathrm{Dy}(\mathrm{hfac})_{3} \mathbf{L}^{2}\right]$ (Fig. 2). As a consequence, the magnetic properties 124 of these two, apparently similar, complexes differ. In zero external dc field, [Dy (hfac) $)_{3} \mathbf{L}^{2}$ ] behaves as a SMM with the apparition of a frequency-dependent out-of26 phase component of the ac susceptibility. Such signal is absent for [Dy(hfac $)_{3} \mathbf{L}^{\mathbf{1}}$ ] 127 which is not a SMM, as far as the crystalline condensed phase is concerned. The 128 hydrogen-bonding network plays a crucial role in the modification of this behavior. 129 Magnetic measurements in solution reveal the true nature of the complexes. Of 130 course, one must be sure that the complexes are stable in solution. They both behave 131 the same, as molecular magnets. This proves two important characteristics: (1) the 132 behavior of SMM can be preserved in solution. This is an important issue since one may say that the observed behavior is truly of molecular origin and then the molecular 134 magnet can be manipulated. (2) The destruction of the intermolecular network by 135 dissolution restores the molecular property. The absence of SMM behavior in crys136 talline condensed phase must be taken carefully, and the impact of the crystal packing 137 must be analyzed prior any hasty conclusion.

The ground multiplet ground state ${ }^{6} \mathrm{H}_{15 / 2}$ of Dy(III) splits under the effect of 139 crystal field in several sublevel characterized by pure $M_{J}$ levels or a mixture of $M_{J}$ 140 levels depending on the symmetry of the ligand field. In this frame, the effective $1 / 2$ 

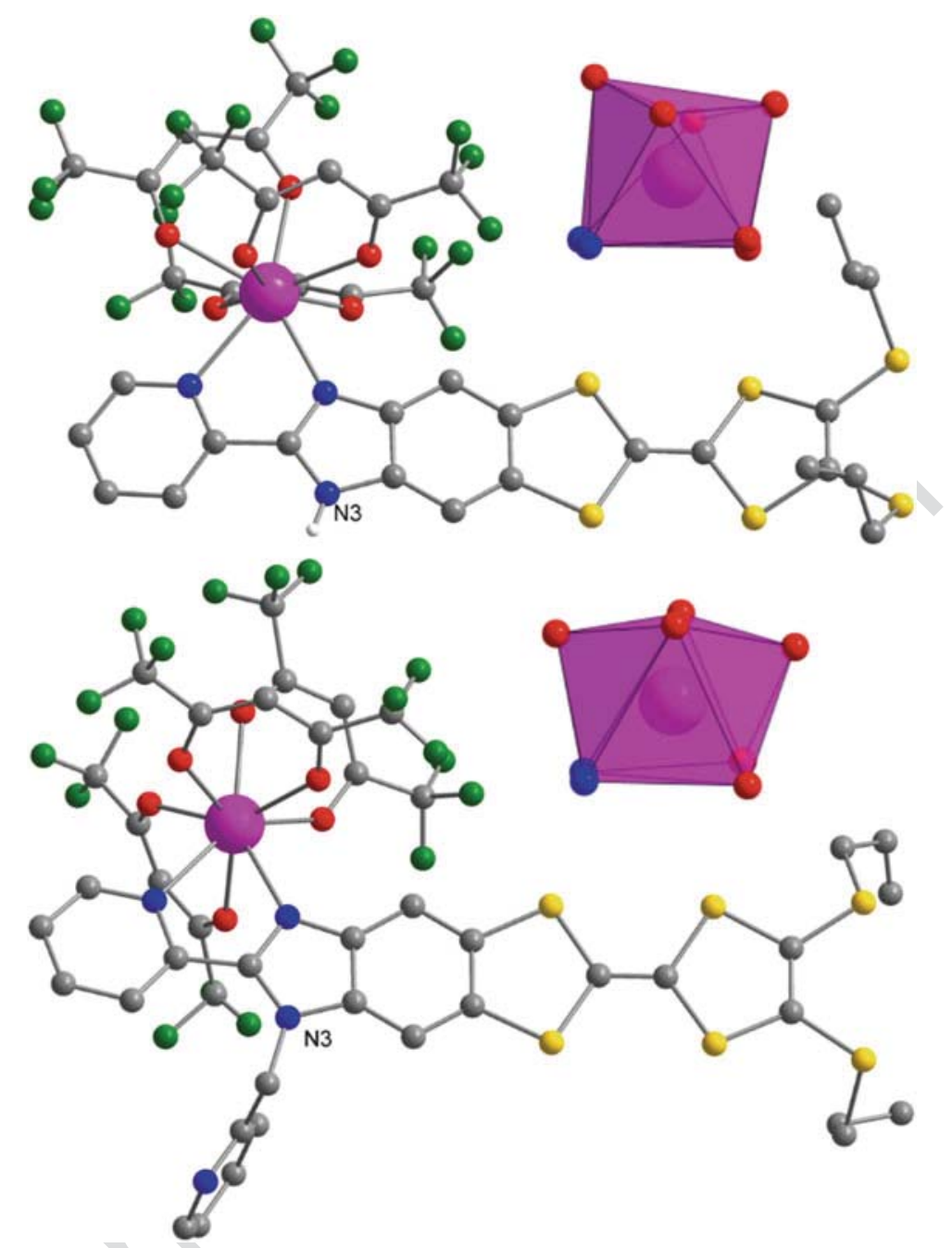

Fig. 2 Representation of the complexes $\left[\mathrm{Dy}(\mathrm{hfac})_{3} \mathbf{L}^{\mathbf{1}}\right]$ (top) and $\left[\mathrm{Dy}(\mathrm{hfac})_{3} \mathbf{L}^{2}\right]$ (bottom) with the alkylated nitrogen atom N3. Coordination polyhedra are also represented

is often used to describe these Kramers sublevels. Then, the Kramers ground state 141 possesses an effective spin 1/2 with an effective $g$-tensor in the reference frame of 142 the complex. It is not difficult to show that for the two Ising components $M_{J}= \pm 15 / 2 \quad 143$ of the ${ }^{6} \mathrm{H}_{15 / 2}$ multiplet the $\boldsymbol{g}$-tensor is characterized by $g_{x}=g_{y}=0$ and $g_{z}=20$ with 144 $z$ the axis of projection. Experimentally, the orientation and the amplitude of the $\boldsymbol{g}$ - 145 tensor are available under certain conditions: the complex must crystallize in the 146 triclinic system with only one Dy(III) crystallographic site. Measurements of the 147 magnetization on an oriented single crystal in three perpendicular planes as a 148 function of the angle $(\theta)$ between the magnetic field $(H)$ with the axes of the single 149 
crystal allow the determination without ambiguity of the $\boldsymbol{g}$-tensor. The magnetic susceptibility in a plane can be fitted with the following equation:

$$
\chi_{\mathrm{M}} T=\frac{M T}{H}=\chi_{\alpha \alpha} T \cos ^{2} \theta+\chi_{\beta \beta} T \sin ^{2} \theta+2 \chi_{\alpha \beta} T \sin \theta \cos \theta
$$

152

Fig. 3 Angular dependence of $\chi_{\mathrm{M}} T$ measured at $2 \mathrm{~K}$ for $\left[\mathrm{Dy}(\mathrm{hfac})_{3} \mathbf{L}^{\mathbf{1}}\right]$ with a $1 \mathrm{kOe}$ magnetic field in three perpendicular planes $(X Y$, $Z Y$, and $X Z$ ). In inset a schematic representation of a single crystal of [Dy (hfac) ${ }_{3} \mathbf{L}^{\mathbf{1}}$ ] with crystallographic axes in the frame of the single crystal

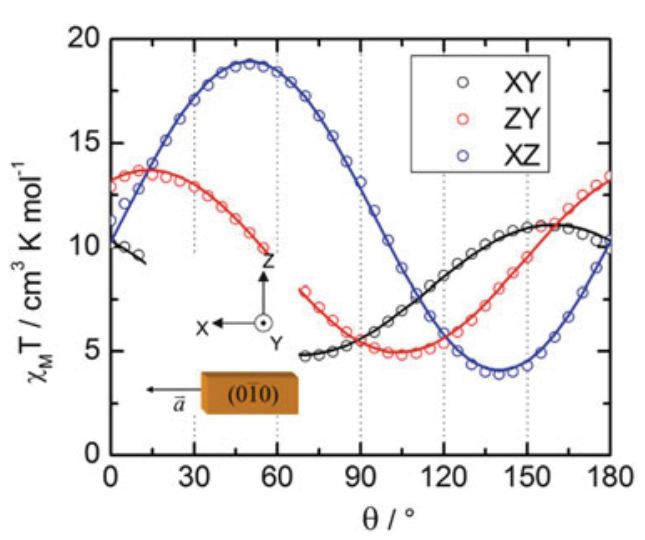


Fig. 4 (Top) orientations of the experimental $z$ magnetic axis represented in black for $\left[\mathrm{Dy}(\mathrm{hfac})_{3} \mathbf{L}^{\mathbf{1}}\right.$ ] with the calculated orientation for different positions of the hydrogen atom $(\mathrm{O}-\mathrm{H}$ in red, $\mathrm{N}-\mathrm{H}$ in blue, and middle in purple). (Bottom) thermal variations of the experimental (white symbols) and calculated (full-colored lines) $\chi_{\mathrm{M}} T$ within the inset of the experimental and calculated field variation of the magnetization at $2 \mathrm{~K}$

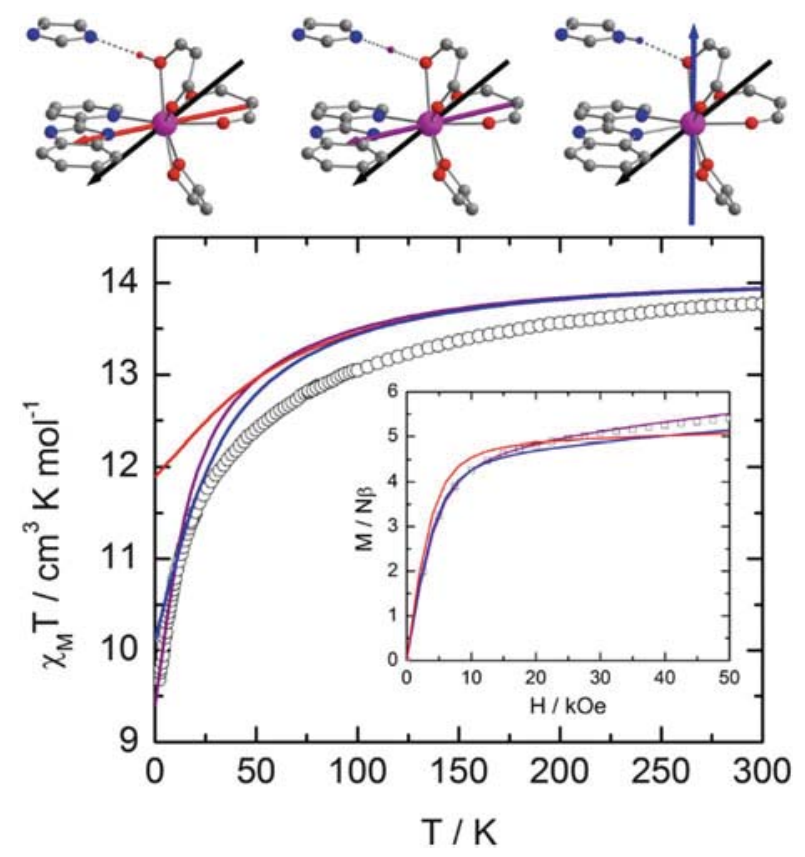

At this stage $\mathbf{L}^{2}$ seems to be a good starting point, but the use of $\mathrm{hfac}^{-}$produces a 176 SMM with relatively low efficiency. Indeed, the energy necessary to reverse the 177 magnetic moment is less than $20 \mathrm{~K}$ (the barrier) and a temperature-independent 178 relaxation process (quantum tunneling of the magnetization) of the order of $100 \mu \mathrm{s} .179$ In order to improve the SMM in keeping this topology, one possibility is to play with 180 the ancillary ligand. Thiophene groups are less electroattractive than $\mathrm{CF}_{3}$, and then 181 the substitution of one $\mathrm{CF}_{3}$ by one thiophene should increase the negative charges on 182 coordinated oxygen atoms.

The magnetic properties of [Dy(tta) $\left.{ }_{3} \mathbf{L}^{2}\right]\left(\mathrm{tta}^{-}:\right.$2-thenoyltrifluoroacetonate) have 184 been studied in the crystalline condensed phase and in frozen solution [47]. Qualita- 185 tively, the magnetism corresponds to [Dy(hfac $)_{3} \mathbf{L}^{2}$ ]: it is a SMM in solid state and in 186 solution. Quantitatively, the energy barrier has been multiplied by a factor two and 187 validates our approach. Ab initio calculations showed that the negative charges 188 carried by oxygen atoms are larger, in amplitude, than for [Dy(hfac $\left.)_{3} \mathbf{L}^{\mathbf{2}}\right]\left(\begin{array}{lll}-0.71 & 189\end{array}\right.$ vs. -0.68 in average) according to electrostatic considerations [46, 47]. Interestingly, 190 SHAPE analyses [40] on $\left[\mathrm{Dy}(\mathrm{tta})_{3} \mathbf{L}^{2}\right]$ and $\left[\mathrm{Dy}(\mathrm{hfac})_{3} \mathbf{L}^{2}\right]$ reveal nearly the same 191 distortions. In both structures, Dy(III) resides in SAP environment with 192 $\mathrm{CShM}=0.538$ and 0.597 , respectively. Angular-resolved magnetometry measure- 193 ments show that the anisotropy axis (the easy magnetization axis) is parallel to the 194 most negatively charged direction (Fig. 5). This experimental finding is supported by 195 ab initio calculations with a gap between the calculated and the experimental easy 196 axis of only $7.6^{\circ}$. Furthermore, the calculated $g_{z}(19.5)$ is very close to the Ising limit. 197 The examination of the temperature dependence of the relaxation time of the 198 
Fig. 5 Representation of the molecule $\left[\mathrm{Dy}(\mathrm{tta})_{3} \mathbf{L}^{2}\right]$ avec and the calculated (orange) and experimental (green) magnetic axes. Insert: scheme of the coordination sphere of Dy (III) ion with the calculated charges of the coordinated atoms

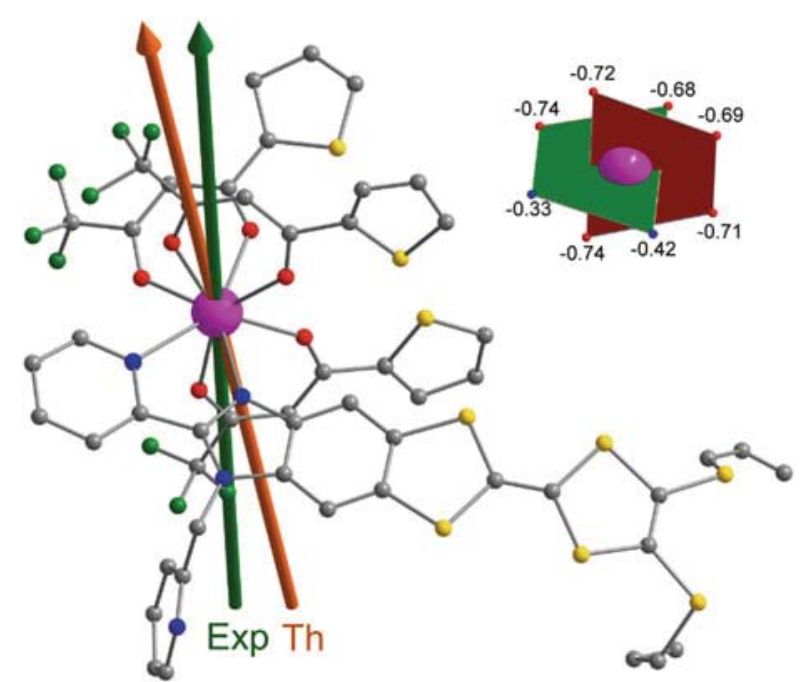

magnetic moment reveals the presence of a thermally activated regime at a high temperature, while the system enters a thermally independent regime below $6 \mathrm{~K}$ (Fig. 6). It can be reproduced with a combination of the Orbach [48] (over the barrier) and tunneling (through the barrier) processes: $\tau^{-1}=\tau_{0}^{-1} \exp (\Delta / T)+\tau_{\mathrm{TI}}^{-1}$ with $\Delta=42 \mathrm{~K}, \tau_{0}=8 \times 10^{-6} \mathrm{~s}$, and $\tau_{\mathrm{TI}}=1.62 \times 10^{-3} \mathrm{~s}$. Dy(III) is a Kramers ion, and the magnetic moment should not be able to tunnel through the barrier: the two Ising components cannot be mixed by modulation of the crystal field. The application of a moderate external dc field $(1 \mathrm{kOe})$ destroys this relaxation path, and the system falls in a pure thermally activated regime with nearly the same activation energy. Additional perturbations must affect the Kramers ground state in zero external dc field to allow the system to oscillate between the "up" and "down" states. In the condensed crystalline state, the molecules are closely packed, and interactions of dipolar origin may propagate through space. This is especially true when someone deals with heavy lanthanides which possess the largest magnetic moments of the periodic table. Transverse component of this internal field can mix the Kramers doublets and facilitate the tunneling. The dilution of the complex in a diamagnetic medium (at low concentration) minimizes this internal field and is supposed to suppress the tunneling. However, one can see on Fig. 6 that dissolution in dichloromethane is not enough: leveling of the relaxation time still persists at low temperature. Compared to the application of an external dc field of $1 \mathrm{kOe}$, which completely lifts the degeneracy of the ground state and destroys the tunneling effect (Fig. 6), in solution, the relaxation time remains rapid (about 100 times faster). The consequence is that, even in solution, the hysteresis loop remains closed in zero field while it is opened up in field (butterfly-shaped hysteresis) at any temperatures above $500 \mathrm{mK}$ [47].

Then, if the closure of the hysteresis loop at the origin does not arise from intermolecular considerations, it might come from inside the complex. Dysprosium 
Fig. 6 Log-scale

representation of the thermal variation of the relaxation time of $\left[\mathrm{Dy}(\mathrm{tta})_{3} \mathbf{L}^{2}\right]$ in solid state (full symbols) and in solution (empty symbols), in zero external dc field

(circles) and under $1 \mathrm{kOe}$ external dc field (squares). Solid red lines correspond to the best fitted curves with a modified Arrhenius law at zero field and a Arrhenius law in field

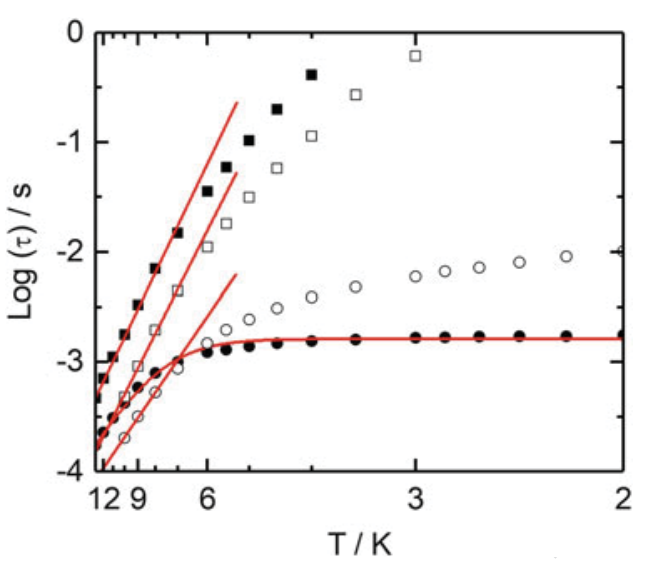

is one of the elements in the periodic which consists of different and stable isotopes 226 $\left({ }^{161} \mathrm{Dy},{ }^{162} \mathrm{Dy},{ }^{163} \mathrm{Dy}\right.$, and $\left.{ }^{164} \mathrm{Dy}\right)$ in quasi-equivalent natural abundance. Two of 227 them, with an even mass number, possess a nuclear spin $(I=0)$, and the two others 228 have a nuclear spin $I=5 / 2$. We have then decided to study the influence of this 229 nuclear spin on the relaxation of the electronic magnetic moment [49] coupled with 230 magnetic dilution. Hyperfine interactions and dilution are known to affect the 231 relaxation of the magnetic moments [50-52]. Clearly, metal-centered isotopic 232 enrichment modifies the relaxation rate in the quantum regime (Fig. 7).

Below $6 \mathrm{~K}$ when the system enters in the quantum regime, the relaxation time of 234 the magnetic moment is ten times slower for the isotopically enriched complex [ ${ }^{164} 235$ $\left.\operatorname{Dy}(\mathrm{tta})_{3} \mathbf{L}^{2}\right](I=0)$ than for the isotopically enriched complex $\left[{ }^{161} \mathrm{Dy}(\mathrm{tta})_{3} \mathbf{L}^{2}\right](I=5 / 236$ $2)$. This is true in zero external dc field in the condensed crystalline phase but also 237 when the enriched complex is diluted in a diamagnetic isomorphous crystalline 238 matrix $\left(\left[{ }^{164} \mathrm{Dy}_{0.04} \mathrm{Y}_{0.96}(\mathrm{tta})_{3} \mathbf{L}^{2}\right] \cdot \mathrm{C}_{6} \mathrm{H}_{14}\right.$ vs. $\left.\left[{ }^{161} \mathrm{Dy}_{0.03} \mathrm{Y}_{0.97}(\mathrm{tta})_{3} \mathbf{L}^{2}\right] \cdot \mathrm{C}_{6} \mathrm{H}_{14}\right)$. The dra- 239 matic difference is that the dilution in a diamagnetic medium of these isotopically 240 enriched complexes slows the relaxation enough to observe the opening of the 241 hysteresis loop at the origin for the ${ }^{164}$ Dy derivative and not for the ${ }^{161}$ Dy derivative. 242 At this stage we proved that isotopes chemistry drives some electronic properties. 243 Nevertheless, one must keep in mind that the hysteresis (the memory) in the absence 244 of an external stimulus shows up only when the molecules are far away from each 245 other. Thus, the deposition of juxtaposed SMMs on surfaces can lead to unexpected 246 results because they will behave, in a certain manner, collectively and not individ- 247 ually (Fig. 8).

In addition, we recently investigated the magnetism of the last two stable enriched 249 complexes $\left[{ }^{162} \mathrm{Dy}(\mathrm{tta})_{3} \mathbf{L}^{2}\right]$ and $\left[{ }^{163} \mathrm{Dy}(\mathrm{tta})_{3} \mathbf{L}^{2}\right]$ [53]. $\left[{ }^{162} \mathrm{Dy}(\mathrm{tta})_{3} \mathbf{L}^{2}\right]$ is the copy 250 paste of $\left[{ }^{164} \mathrm{Dy}(\mathrm{tta})_{3} \mathbf{L}^{2}\right]$ because the nuclear spin of Dy(III) is zero in both cases. 251 The nuclear spins of ${ }^{163}$ Dy and ${ }^{161}$ Dy are indeed equal $(I=5 / 2)$, but the 252 hyperfine coupling constant $\mathrm{A}_{\mathrm{HF}}$ differs $[54,55]$ and then the relaxation rate 253 affected. This is perceptible in condensed crystalline phase with $\left[{ }^{163} \mathrm{Dy}(\mathrm{tta})_{3} \mathbf{L}^{\mathbf{2}}\right] 254$ 
Fig. 7 Frequency dependences of $\chi_{\mathrm{M}}{ }^{\prime \prime}$ of [ ${ }^{164}$ Dy $\left.(\mathrm{tta})_{3} \mathbf{L}^{2}\right]$ and $\left[{ }^{161} \mathrm{Dy}\right.$ (tta) $\left.{ }_{3} \mathbf{L}^{2}\right]$ in zero field in the temperature range $2-14 \mathrm{~K}$
Fig. 8 Normalized magnetic hysteresis loops measured at $460 \mathrm{mK}$ for [ ${ }^{164}$ $\left.\mathrm{Dy}_{0.04} \mathrm{Y}_{0.96}(\mathrm{tta})_{3} \mathbf{L}^{2}\right] \cdot \mathrm{C}_{6} \mathrm{H}_{14}$ (red line) and [ ${ }^{161}$

$\left.\mathrm{Dy}_{0.03} \mathrm{Y}_{0.97}(\mathrm{tta})_{3} \mathbf{L}^{2}\right] \cdot \mathrm{C}_{6} \mathrm{H}_{14}$ (blue line)
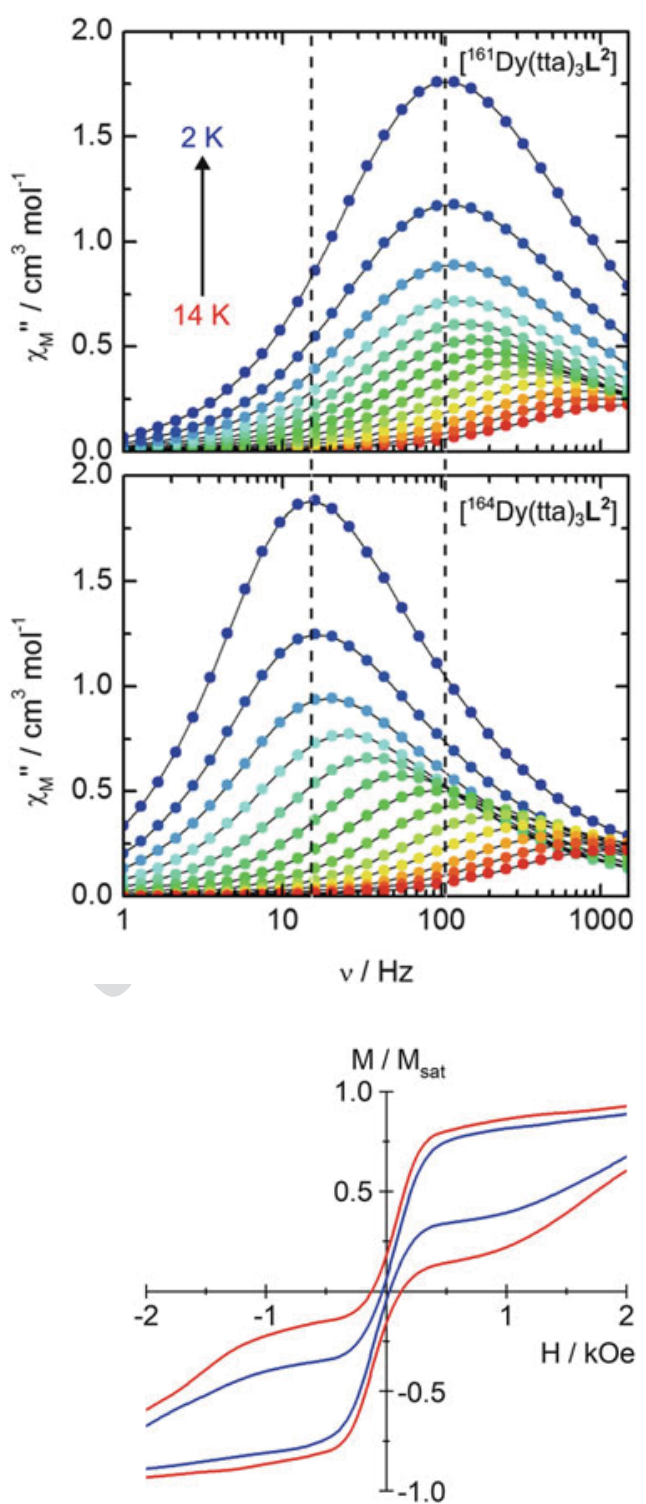

255 slightly faster than $\left[{ }^{161} \mathrm{Dy}(\mathrm{tta})_{3} \mathbf{L}^{2}\right]$, but at this stage, the relaxation is essentially 256 driven by intermolecular interactions. Once diluted, $\left[{ }^{161} \mathrm{Dy}_{0.05} \mathrm{Y}_{0.95}(\mathrm{tta})_{3} \mathbf{L}^{2}\right] \cdot \mathrm{C}_{6} \mathrm{H}_{14}$ 257 is about ten times slower than $\left[{ }^{163} \mathrm{Dy}_{0.05} \mathrm{Y}_{0.95}(\mathrm{tta})_{3} \mathbf{L}^{2}\right] \cdot \mathrm{C}_{6} \mathrm{H}_{14}$. Sign and/or amplitude 258 of the hyperfine coupling seem to play also a fundamental role on the relaxation in 259 quantum regime. 
There are additional TTF-Dy(III) $\left[\mathrm{N}_{2} \mathrm{O}_{6}\right]$ mononuclear complexes which behave as 261 SMMs in the literature. Also, higher coordination number, typically $\mathrm{N}_{3} \mathrm{O}_{6}$, has been 262 envisaged with less success. Environment such as $\mathrm{O}_{8}$ for which the charge distribu- 263 tion is more symmetric has also been investigated. Some of these complexes are 264 stricto sensu (chemically) mononuclear complexes, but some of them are polynu- 265 clear complexes but in which the distances between metallic centers are so large that 266 we can consider they are mononuclear from a magnetic point of view. In other 267 words, there are no interactions between those centers. Such complexes might be 268 described as an assembly of mononuclear SMMs.

\subsection{Nitrogen-Based Donor-Acceptor Type Dyads}

The first example we want to introduce is based on a similar TTF ligand with a 271 benzothiazole group. The ligand $\mathbf{L}^{\mathbf{3}}$ ( $\mathbf{L}^{\mathbf{3}}=4$-[6-(1,3-benzothiazol-2-yl)pyridin-3- 272 yl]-4',5'-bis(methyl-thio)tetrathiafulvene) is similar to $\mathbf{L}^{\mathbf{1}}$ with however no possible 273 intermolecular hydrogen bond [56]. Such benzothiazole group might also be of 274 interest to realize photoswitchable conductors and photoelectric conversion mate- 275 rials [57]. Reaction of $\mathbf{L}^{\mathbf{3}}$ with [ $\left.\mathrm{Ln}(\mathrm{tta})_{3}\right] \cdot 2 \mathrm{H}_{2} \mathrm{O}$ gives [ $\mathrm{Ln}(\mathrm{tta})_{3} \mathbf{L}^{3}$ ] complex which 276 crystallize in the P-1 triclinic space group for light elements and in the P2 ${ }_{1} / \mathrm{a} 277$ monoclinic space group for heavy elements. For intermediate Dy(III), the two 278 polymorphs can be obtained. Like in the previous section, Dy(III) ion is in a $\mathrm{N}_{2} \mathrm{O}_{6} 279$ environment (Fig. 9) with a square antiprismatic idealized coordination polyhedron. 280 The complexes behave as SMMs with slightly different energy barriers ( $57 \mathrm{~K} 281$ vs. $42 \mathrm{~K}$ ). The coordination polyhedron is slightly more distorted in the triclinic 282 phase than in the monoclinic one with however the highest energy barrier. One 283 should then conclude that there is no direct correlation between symmetry and 284 activation energy. Additional factors, which are not that clear and yet to be identi- 285 fied, influence the energy splitting diagram. Quantum chemistry calculations qual- 286 itatively reproduce this experimental fact: the first excited state is located higher in 287 energy in the monoclinic phase than in the triclinic. These barriers are also similar to 288 the one found for $\left[\mathrm{Dy}(\mathrm{tta})_{3} \mathbf{L}^{\mathbf{2}}\right.$ ] (due the similarities between the two environments). 289 Here again, the calculated and the experimental orientation of the easy magnetic axis 290 are in very good agreement with less than $10^{\circ}$ of mismatch and an orientation in the 291 most negatively charged direction. The dilution+enrichment protocol has been 292 applied to both polymorphs, but only nuclear spin-free isotopes were employed to 293 slow down the relaxation as much as we could. The same receipts give the same 294 results: the hysteresis loops open in zero field for the enriched and diluted 295 complexes. 

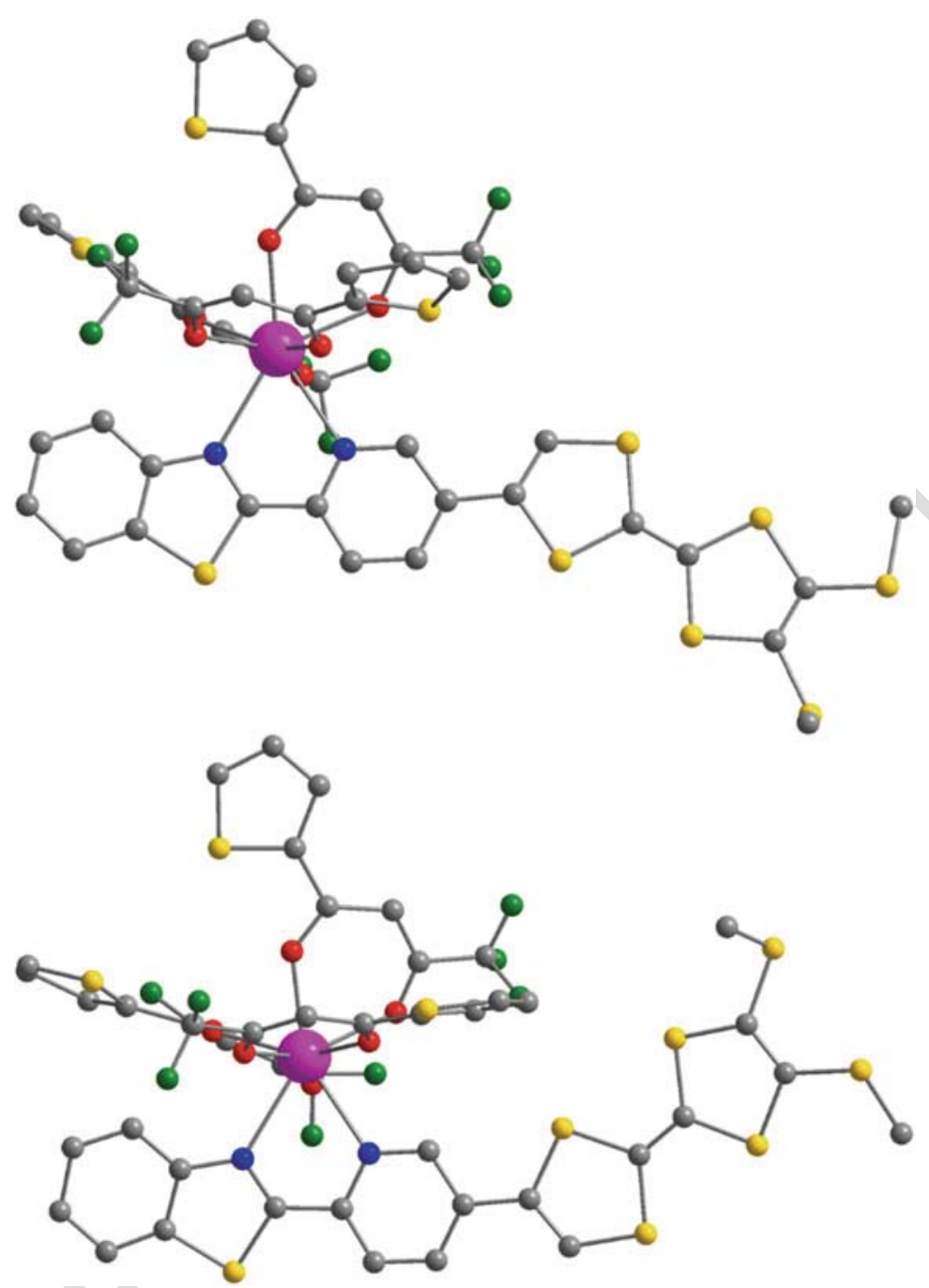

Fig. 9 Representation of the complex $\left[\mathrm{Dy}(\mathrm{tta})_{3} \mathbf{L}^{3}\right]$ in the triclinic (top) and monoclinic (bottom) forms

297 All the TTF-based ligand envisaged so far could be coordinated only by one 298 metal center, so we imagined and designed new TTF-based ligand to incorporate, in 299 a bridging ligand, different coordination sites. The ideas behind were to (1) select 300 different metals in incorporating different chelating sites (e.g., tris-) and (2) to 301 accommodate the same metal in different environments to tune its magnetic prop302 erties (Fig. 10) [58].

303 When reacted with $\left[\mathrm{Dy}(\mathrm{hfac})_{3}\right] \cdot 2 \mathrm{H}_{2} \mathrm{O}, \mathrm{L}^{4}$ coordinates from both bischelating sites 304 to form $\left[\mathrm{Dy}_{2}(\mathrm{hfac})_{6} \mathbf{L}^{\mathbf{4}}\right]$ neutral complex. Each Dy(III) ion is surrounded by six 


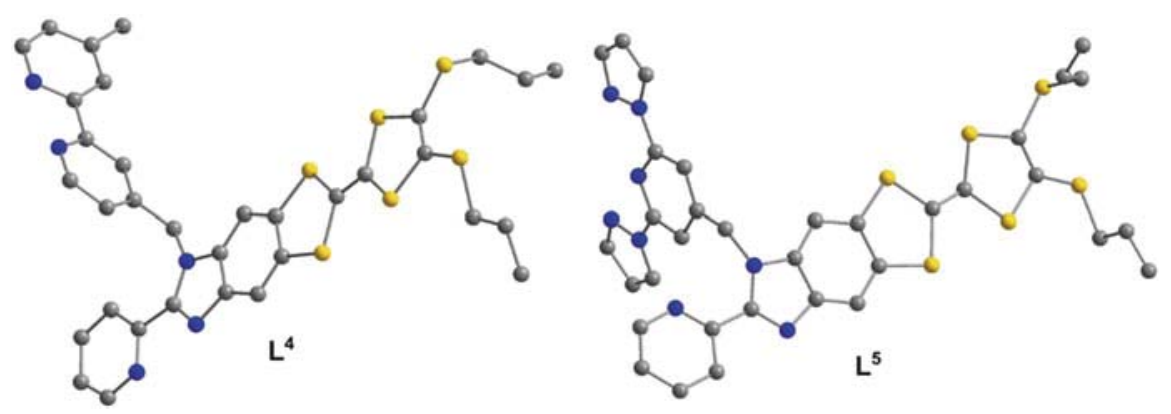

Fig. 10 Representations of $\mathbf{L}^{4}$ and $\mathbf{L}^{5}$ ligands

oxygen and two nitrogen atoms and lies in almost the same $\mathrm{N}_{2} \mathrm{O}_{6} \mathrm{D}_{4 \mathrm{~d}}$ environment 305 and is separated by more than $10 \AA$ [58]. From a magnetic point of view, these two 306 sites should behave the same, and this is what is observed. Both behave as SMMs in 307 zero external dc field, and the extended Debye analysis [59] reveals only one 308 relaxation process. Seventy percent of the magnetic moments relax at the same 309 frequency. The relaxation is however too fast in zero field to be quantitatively 310 analyzed. In applying an external field to suppress the thermally independent regime, 311 only one relaxation time that includes both sites is identified. At the optimum field, 312 i.e., the external field for which the relaxation is the slowest (800 Oe), the 313 thermal variation of the relaxation time does not follow the Arrhenius law expected 314 for the Orbach process [60] but can be easily reproduced with a Raman process 315 ( $\tau=\mathrm{CT}^{\mathrm{n}}, \mathrm{C}=4.8 \times 10^{-3}$, and $n=6.26$ ). This tends to prove that the relaxation 316 does not occur through the first excited state, at least, as long as the in-field relaxation 317 is concerned.

The reaction of $\left[\mathrm{Dy}(\mathrm{hfac})_{3}\right] \cdot 2 \mathrm{H}_{2} \mathrm{O}$ with $\mathbf{L}^{\mathbf{5}}$ leads to dinuclear species 319 $\left(\left[\mathrm{Dy}_{2}(\mathrm{hfac})_{6} \mathbf{L}^{\mathbf{5}}\right]\right)$ with two different coordination polyhedra [61], $\mathrm{N}_{2} \mathrm{O}_{6} 320$ $\left(C_{\text {CShM }}{ }_{\text {SAPR-8 }}\left(D_{4 d}\right)=0.435\right)$ and $\mathrm{N}_{3} \mathrm{O}_{6}\left(C_{\text {CShM }}\right.$ TCTPR-9 $\left.\left(D_{3 h}\right)=0.586\right)$. The $\mathrm{N}_{2} \mathrm{O}_{6} 321$ sites behave in a standard way (SMM in zero external field), while the 322 nonacoordinated site does not show any out-of-phase signal in zero external field. 323 The application of a moderate external dc field slows down the relaxation with the 324 emergence of two identifiable processes that can be safely attributed to the two 325 different sites. An extended Debye model featuring two relaxation times has been 326 employed to treat the ac data. Interestingly, the analyses reveal the ratio of the 327 magnetic susceptibility which relaxes at the two relaxation time to be close to 50:50 328 in agreement with the chemical structure. Furthermore, the energy barrier for the 329 octacoordinated site is in good agreement with its mononuclear equivalent 330 [45]. From a chemical point of view, it was interesting to look for site selectivity 331 with regard to different $\mathrm{Dy}(\beta \text {-diketonate })_{3}$ precursors. A 1:1 ratio of $\left[\mathrm{Dy}(\mathrm{hfac})_{3}\right] \cdot 332$ $2 \mathrm{H}_{2} \mathrm{O}$ and $\left[\mathrm{Dy}(\mathrm{tta})_{3}\right] \cdot 2 \mathrm{H}_{2} \mathrm{O}$ was reacted with $\mathbf{L}^{\mathbf{5}}$, and it forms dinuclear species 333 
334

$\left[\mathrm{Dy}_{2}(\mathrm{hfac})_{3}(\mathrm{tta})_{3} \mathbf{L}^{5}\right]$. The crystal structure of the complex reveals ligand exchange, with the $\mathrm{N}_{2} \mathrm{O}_{6}$ site made of two tta ${ }^{-}$and one $\mathrm{hfac}^{-}$ligands and the $\mathrm{N}_{3} \mathrm{O}_{6}$ site made of one $\mathrm{tta}^{-}$and two hfac ${ }^{-}$ligands. We think this ligand exchange occurs as a consequence of a subtle balance between the size of the metallic precursors and the coordination which leads to a minimum steric hindrance. The magnetic behaviors of these two metallic sites are qualitatively identical to $\left[\mathrm{Dy}_{2}(\mathrm{hfac})_{6} \mathbf{L}^{\mathbf{5}}\right]$ with the $\mathrm{N}_{2} \mathrm{O}_{6}$ site being a SMM in zero field while the $\mathrm{N}_{3} \mathrm{O}_{6}$ site being a SMM only in field [61].

At this stage, it appears that $\mathrm{N}_{2} \mathrm{O}_{6}$ coordination polyhedron around Dy(III)

systematically produces SMMs in zero field. Liu et al. [62] developed a TTF-fused donor-acceptor system based on dipyrido[3,2-a:2',3'-c]phenazine (dppz) which can be reacted with Dy $(\beta \text {-diketonate })_{3}$ precursors $\left(\left[\mathrm{Dy}(\mathrm{hfac})_{3}\right] \cdot 2 \mathrm{H}_{2} \mathrm{O}\right.$ and $\left[\mathrm{Dy}(\mathrm{tta})_{3}\right]$. $2 \mathrm{H}_{2} \mathrm{O}$ ) [63]. Two mononuclear units are obtained with Dy(III) in the standard $\mathrm{N}_{2} \mathrm{O}_{6}$ SAP coordination polyhedron made of three $\beta$-diketonate ligands and one dipyridyl moiety $\left(\mathrm{CShM}_{\mathrm{SAPR}-8}\left(\mathrm{D}_{4 \mathrm{~d}}\right)=0.724\right.$ for the $\mathrm{hfac}^{-}$derivative and $\mathrm{CShM}_{\mathrm{SAPR}-8}\left(\mathrm{D}_{4 \mathrm{~d}}\right)=0.507$ for the tta ${ }^{-}$derivative $)$from the ligand $\mathbf{L}^{\mathbf{6}}\left(\mathbf{L}^{\mathbf{6}}=\right.$ TTFfused dipyrido[3,2-a:2 $\left.2^{\prime}, 3^{\prime}-c\right]$ phenazine). Both compounds behave as SMM in zero field, but they are "faster," and they relax at higher frequencies, than previous $\mathrm{N}_{2} \mathrm{O}_{6}$ systems with however the $\mathrm{tta}^{-}$derivative slower than the hfac${ }^{-}$. Typically, at $2 \mathrm{~K}$, the maximum on the $\chi_{\mathrm{M}}{ }^{\prime \prime}$ vs. $\nu$ curves shows up at $700 \mathrm{~Hz}$ for $\left[\mathrm{Dy}(\mathrm{tta})_{3} \mathbf{L}^{6}\right]$, while it is located above $1,500 \mathrm{~Hz}$ for $\left[\mathrm{Dy}(\mathrm{hfac})_{3} \mathbf{L}^{6}\right]$. To compare, for $\left[\mathrm{Dy}(\mathrm{hfac})_{3} \mathbf{L}^{2}\right]$, the maximum was at $970 \mathrm{~Hz}$ and at $56 \mathrm{~Hz}$ for $\left[\mathrm{Dy}(\mathrm{tta})_{3} \mathbf{L}^{2}\right]$ in the same sample environment. Such comparison, if natural, is however dangerous since in the low-temperature regime, where thermally independent processes take over all the others, the relaxation in the condensed crystalline phase is governed by the combination of magnetic intermolecular interactions (of dipolar origin) and hyperfine coupling. One can say that this $\mathrm{N}_{2} \mathrm{O}_{6}$ topology (three bischelating oxygenate ligand and one bischelating nitrogenated ligand) provides efficient magnets that qualitatively behave the same and quantitatively almost the same. The difference resides in the electron withdrawing or donating ability of the chemical groups on the $\beta$-diketonate ligands.

\section{Oxygen-Based TTF-Based Ligands}

The strong oxophilic characters of lanthanide authorize the synthesis of fully oxygenated coordination polyhedron around metal centers. However, such environment does not, a priori, create the expected dissymmetry of charges to produce SMMs in the specific case of Dy(III) at least as far as $\mathrm{O}_{8}$ environments are concerned. The reaction of $\left[\mathrm{Dy}(\mathrm{hfac})_{3}\right] \cdot 2 \mathrm{H}_{2} \mathrm{O}$ with $4,4^{\prime}, 7,7^{\prime}$-tetra-tert-butyl-2,2'-bi-1,3-benzodithiole-5,5',6,6'-tetrone ligand [64] $\left(\mathbf{L}^{7}\right)$ forms a dinuclear complex $\left[\mathrm{Dy}_{2}(\mathrm{hfac})_{6}\left(\mathrm{H}_{2} \mathrm{O}\right)_{2} \mathbf{L}^{7}\right][65]$. In this complex, two Dy(III) ions, related by an inversion center, in $\mathrm{O}_{9}$ coordination polyhedron, are linked by an acceptor-donor-acceptor triad (Fig. 11). Eight of the nine are coming from bischelating ligands (three hfac ${ }^{-}$and one quinone), and the last one is coming from a water molecule. The intramolecular 


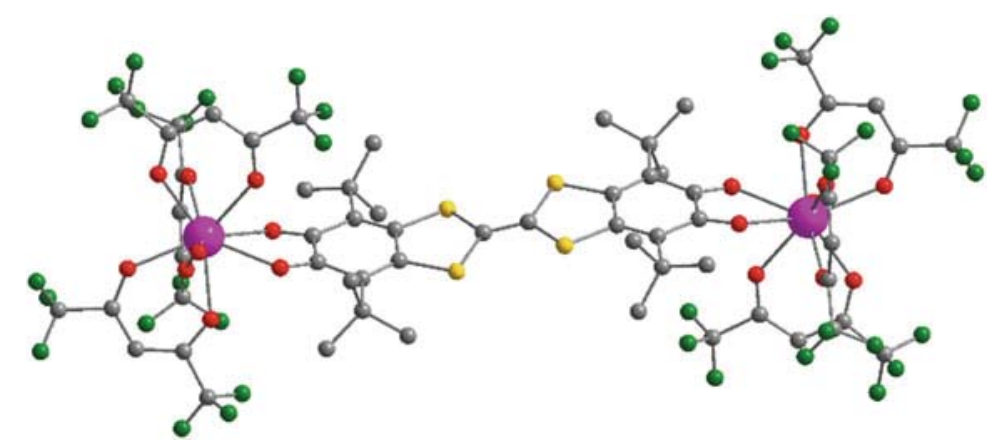

Fig. 11 View of the dinuclear compound $\left[\mathrm{Dy}_{2}(\mathrm{hfac})_{6}\left(\mathrm{H}_{2} \mathrm{O}\right)_{2} \mathbf{L}^{7}\right]$

Dy-Dy distance is close to $17.5 \AA$, so there is no superexchange interaction between 375 the two metals.

In this environment, Dy behaves as a SMM in zero external field. Interestingly, 377 the equivalent complex obtained from the reaction of $\mathbf{L}^{7}$ with $\left[\mathrm{Dy}(\mathrm{tta})_{3}\right] \cdot 2 \mathrm{H}_{2} \mathrm{O}$ does 378 not produce SMM. The steric hindrance of $\mathrm{tta}^{-}$avoids water molecule to coordinate 379 Dy(III), and therefore in this dinuclear complex, the coordination polyhedron is only 380 made of eight oxygen atoms which is probably less suitable to promote axial 381 anisotropy. This simple analysis is counterbalanced by other investigations [66] 382 which clearly demonstrate that $\mathrm{O}_{8}$ environment could perfectly produce SMMs 383 with Dy(III) ions. Probably, the primary approach which consists of considering 384 only the point charge model might be oversimplified. Some authors pointed out with 385 a deeper analysis that dipole and quadrupole moments in the electrostatic potential 386 expansion play a significant role on the magnetic anisotropy [67, 68].

To conclude this section, we would like to briefly discuss one peculiar 388 system. Two different TTF-based ligands are used to produce a dinuclear $\mathrm{Yb} 389$ (III)-based complex $\left[\mathrm{Yb}(\mathrm{tta})_{2} \mathbf{L}^{\mathbf{8}} \mathbf{L}^{\mathbf{9}}\right]_{2}$ [69]. The redox active ligand 4,5-bis 390 (thiomethyl)-4'-carboxylictetrathiafulvalene $\left(\mathbf{L}^{\mathbf{8}}\right)$ is bridging two $\mathrm{Yb}(\mathrm{III})$ ions 391 through $\mu_{2}\left(\eta_{1}, \eta_{2}\right)$ oxygen atoms, and 4,5-bis(thiomethyl)-4'-ortho-pyridyl-N- 392 oxide-carbamoyl-tetrathiafulvalene $\left(\mathbf{L}^{\mathbf{9}}\right)$ is terminal (Fig. 12). The coordination 393 sphere around each $\mathrm{Yb}(\mathrm{III})$ is made of eight oxygen atoms, and the two ions are 394 separated by only $3.89 \AA$.

The static magnetic properties reveal what could be analyzed as a sign of 396 ferromagnetic interactions between the two ${ }^{2} \mathrm{~F}_{7 / 2}$ multiplet ground states. Indeed, 397 on cooling from room temperature, $\chi_{\mathrm{M}} T$ decreases continuously in agreement with 398 the thermal depopulation of $M_{J}$ states, passes through a broad minimum at $9 \mathrm{~K}$, and 399 then slightly increases on cooling further down to the lowest temperature. We have 400 attempted to fit the $\chi_{\mathrm{M}} T$ vs. $T$ plot taking into account the crystal field effects by the 401 extended Stevens operators technique [48] and the interaction between magnetic 402 moments. The Hamiltonian to consider is the following: 
Fig. 12 View of the dinuclear compound $[\mathrm{Yb}$ (tta) $\left.{ }_{2} \mathbf{L}^{8} \mathbf{L}^{9}\right]_{2}$

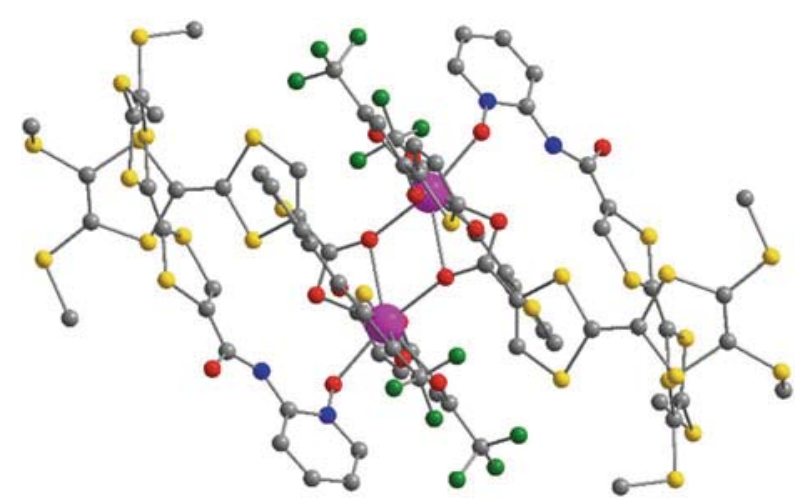

$$
\begin{aligned}
\widehat{H}= & \sum_{i=1}^{2}\left(B_{2}^{0} \widehat{\boldsymbol{O}_{2}^{\boldsymbol{i}}}+B_{2}^{2} \widehat{\boldsymbol{O}_{2}^{2} \boldsymbol{i}}+B_{4}^{0} \widehat{\boldsymbol{O}_{4}^{\boldsymbol{i}}}+B_{4}^{2} \widehat{\boldsymbol{O}_{4}^{2} \boldsymbol{i}}+B_{4}^{4} \widehat{\boldsymbol{O}_{4}^{4} \boldsymbol{i}}+B_{6}^{0} \widehat{\boldsymbol{O}_{\boldsymbol{\sigma}}^{\boldsymbol{i}}}+B_{6}^{2} \widehat{\boldsymbol{O}_{\boldsymbol{\sigma}}^{2} \boldsymbol{i}}+B_{6}^{4} \widehat{\boldsymbol{O}_{\boldsymbol{\sigma}}^{4} \boldsymbol{i}}+B_{6}^{6} \widehat{\boldsymbol{O}_{\boldsymbol{\sigma}}^{2} \boldsymbol{i}}\right) \\
& +\beta\left(g_{J} \widehat{\boldsymbol{J}}_{\boldsymbol{I}}+g_{J} \widehat{\boldsymbol{J}_{2}}\right) \cdot \vec{H}-J \widehat{\boldsymbol{J}_{\boldsymbol{I}}} \cdot \widehat{\boldsymbol{J}_{\boldsymbol{2}}}
\end{aligned}
$$

The first line corresponds to the crystal field effect at the two lanthanide sites with $405 \widehat{\boldsymbol{O}_{k}^{q}}$ the operator equivalents which can be expressed as polynomials of the total 406 angular momentum matrices $\left(\boldsymbol{J}^{2}, \boldsymbol{J}_{z}, \boldsymbol{J}_{+}\right.$, and $\left.\boldsymbol{J}_{-}\right)$associated with the ${ }^{2} \mathrm{~F}_{7 / 2}$ multiplet 407 ground state. The second line corresponds to the Zeeman effects on $\boldsymbol{J}_{\boldsymbol{i}}$ which are 408 coupled through $J$. A homemade program has been developed to fit the magnetic 409 data. Surprisingly a fairly good agreement (Fig. 13) is obtained without any inter410 action $\left(J=0 \mathrm{~cm}^{-1}\right)$, so one can consider this dimer as two isolated $\mathrm{Yb}$ (III) centers. 411 The wave function analysis reveals that the Kramers ground state is the pure $412 M_{J}= \pm 7 / 2$ component, separated only by $2.6 \mathrm{~cm}^{-1}$ from the first excited state $413 M_{J}= \pm 1 / 2$. The stabilization of the largest $M_{J}$ component can be viewed in the 414 frame of point charge model. The carboxylate group acts as a tweezer which projects 415 the -1 charge in a plane containing two $\mathrm{hfac}^{-}$ligands (Fig. 12). Then, ligand 416 charges are condensed in a plane around this prolate ion (Fig. 1) and stabilize the 417 largest $M_{J}$ doublet state.

418 As a consequence of this Ising-type anisotropy, the complex behaves as a SMM 419 with however a small energy barrier $(21 \mathrm{~K})$ determined from the temperature 420 dependence of the relaxation time. This value can be compared with estimated gap 421 between the ground and the first excited states (see above, $\sim 4 \mathrm{~K}$ ) from DC magnetic 422 measurements. To support this interpretation, luminescence provides a unique tool to 423 probe energy levels. The low-temperature $(77 \mathrm{~K})$ excitation of the sample 424 at $20,000 \mathrm{~cm}^{-1}$ sensitizes the ${ }^{2} \mathrm{~F}_{5 / 2} \rightarrow{ }^{2} \mathrm{~F}_{7 / 2}$ transitions in the range of $42510,400-9,400 \mathrm{~cm}^{-1}$. The excitation corresponds to LLCT (ligand-to-ligand charge 426 transfer) and highlights the role of antenna played by the redox-active TTF ligands. 427 We must mention that Dy(III) luminescence cannot be probed with TTF-based 428 ligand since the emission lines fall in the absorption bands of the ligands. The 
Fig. 13 Temperature dependences of $\chi_{\mathrm{M}} T$ (open circles) with the best fitted curve (red line)

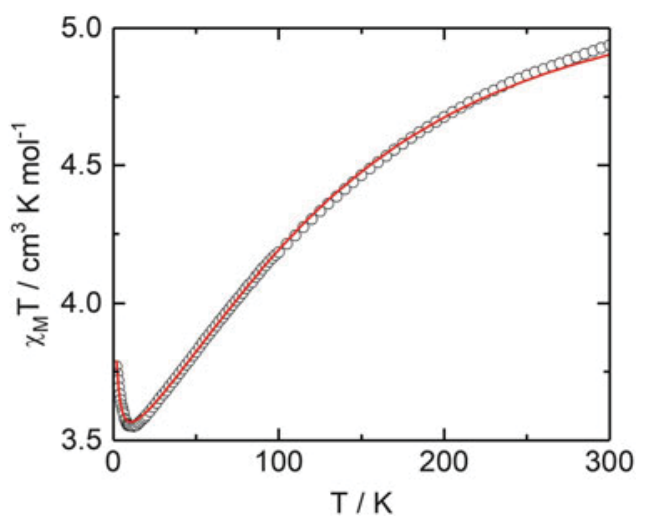

emission profile can be deconvoluted in four transitions $(9,703,9,936,10,197$, and 429 $\left.10,213 \mathrm{~cm}^{-1}\right)$. The gap between the two most energetic transitions $(23 \mathrm{~K})$ gives the 430 exact gap between the Kramers doublet ground state and the first excited state. It is 431 almost in perfect agreement with magnetism.

\section{Polynuclear TTF-Dy(III) SMMs}

One question emerges from the previous paragraph. Does the nonexistence of 434 interactions between $\mathrm{Yb}(\mathrm{III})$ in $\mathrm{Yb}$ derivative $\left[\mathrm{Yb}(\mathrm{tta})_{2} \mathbf{L}^{\mathbf{8}} \mathbf{L}^{\mathbf{9}}\right]_{2}$ can be generalized 435 to other lanthanide? The synthesis of $\left[\mathrm{Dy}(\mathrm{tta})_{2} \mathbf{L}^{\mathbf{8}} \mathbf{L}^{\mathbf{9}}\right]_{2}$, isostructural of Yb derivative, 436 provides an answer [70]. On cooling, $\chi_{\mathrm{M}} T$ vs. $T$ plot passes through a broad 437 minimum at $16 \mathrm{~K}$ that cannot be reproduced without taking into account interactions. 438 The best fits are obtained with a ferromagnetic interaction $J=2.98 \times 10^{-3} \mathrm{~cm}^{-1}$. 439 This interaction is very weak with respect to the energy engaged in crystal field 440 splitting (hundreds of wave numbers). In this frame the Kramers ground state for 441 each Dy(III) ion corresponds to more than $99 \%$ of the $M_{J}= \pm 15 / 2$. In this effective 442 spin-1/2 model, one expects $g=20$ in one direction and 0 in a perpendicular plane. 443 Then, the coupling of dipolar origin between the two magnetic moment can be easily 444 calculated from the Hamiltonian $\widehat{H}=-J_{d d} \widehat{\boldsymbol{\sigma}_{\mathbf{I}}} \cdot \widehat{\boldsymbol{\sigma}_{\mathbf{2}}}$ where $\widehat{\boldsymbol{\sigma}_{i}}$ are the operators 445 associated with the effective $1 / 2$ and $J_{d d}=-\left(\mu_{0} g^{2} \beta^{2} / 4 \pi h c r^{3}\right)\left(1-3 \cos ^{2} \theta\right) \mathrm{cm}^{-1} 446$ ( $r$ is the distance between the metal centers, and $\theta$ is the angle between the anisotropy 447 axis and the $r$ vector). Such interaction can be ferro- or antiferromagnetic depending 448 on $\theta$. The amplitude can also be rather large at short distances, with $r=4 \AA J_{d d} 449$ varies from -2 to $+5 \mathrm{~cm}^{-1}$, to compare with $J=0.67 \mathrm{~cm}^{-1}$ estimated from DC 450 measurements in the same spin-1/2 model $\left(2.98 \times 10^{-3} \times 15 \times 15\right)$. Transferred to 451 $\mathrm{Yb}$ (III) system, the interaction of dipolar origin is more than six times stronger in the 452 very hypothetical case of identical $\theta$. Taking into account the interaction between the 453 two Ising centers, we can describe the ground state with two components: $|\uparrow \uparrow\rangle$ and 454 
455

$|\downarrow \downarrow\rangle$ separated by $J / 2\left(0.335 \mathrm{~cm}^{-1}\right)$ from the excited state described by $|\uparrow \downarrow\rangle$ and $|\downarrow \uparrow\rangle$. The complex is a SMM. However, the thermal variation of the relaxation time at low temperature is very different from what we are used to observe on mononuclear complexes. Indeed, there is no leveling of the relaxation time on cooling in zero external dc field down to $2 \mathrm{~K}: \tau$ increases continuously on cooling. This is certainly the consequence of the thermal population of the four levels. Remarkably, within an external DC field, $\tau$ does not greatly vary. This is a consequence of the condensation of the four states on few tenths of wave numbers.

The implication of magnetic interactions on slow relaxation dynamics in dimers is confirmed by other investigations on TTF-based Dy(III) dinuclear complexes. The reaction of tetrathiafulvalene-3-pyridine-N-oxide ligand $\left(\mathbf{L}^{\mathbf{1 0}}\right)$ with $\left[\mathrm{Dy}(\mathrm{tta})_{3}\right] \cdot 2 \mathrm{H}_{2} \mathrm{O}$ gives the centrosymmetric complex $\left[\mathrm{Dy}(\mathrm{tta})_{3} \mathbf{L}^{\mathbf{1 0}}\right]_{2}[39]$. The $\chi_{\mathrm{M}} T$ vs. $T$ plot shows strong antiferromagnetic interactions between ${ }^{6} \mathrm{H}_{15 / 2}$ multiplets. In the effective spin-1/2 model, the interaction is estimated at $-2.3 \mathrm{~cm}^{-1}$ with a $g$ value (19.2) close to the Ising limit (20). The nonmagnetic ground state is then described by $|\uparrow \downarrow\rangle$ and $|\downarrow \uparrow\rangle$, with the first excited state $(|\uparrow \uparrow\rangle$ and $|\downarrow \downarrow\rangle)$ at $1.3 \mathrm{~cm}^{-1}$. Despite the nonmagnetic nature of the ground state, $\left[\mathrm{Dy}(\mathrm{tta})_{3} \mathbf{L}^{\mathbf{1 0}}\right]_{2}$ behaves as a SMM (Fig. 14). The thermal variation of the relaxation time $\tau$ does not follow a simple mathematical law since various energy levels are involved at temperatures as low as $2 \mathrm{~K}$. The application of an external dc field corroborates the interpretations based on $\mathrm{dc}$ measurements. The field behavior of $\tau$ does reflect the low-level energy diagram. At low field and temperatures below $8 \mathrm{~K}, \tau$ decreases with the field (Fig. 15) with

a clear dip at $1.6 \mathrm{kOe}$. At such temperatures, the first magnetically active $(|\uparrow \uparrow\rangle$ and $|\downarrow \downarrow\rangle)$ ) excited states are thermally populated. It must be pointed out that the transition between these two states necessitates to flip simultaneously both magnetic moments, so the transition probability is very small and the relaxation time long. On increasing the magnetic field, there is a crossing between levels (Fig. 15), and, at the intersection, transition between two states involves "only" to flip one magnetic moment, and the relaxation time shortens. The minimum of $\tau$ should occur at a field which can be related to the interaction between Dy(III). With $J=-2.3 \mathrm{~cm}^{-1}$, the crossing should occur at $1.3 \mathrm{kOe}$ which relatively close to the measured value. This in-field behavior

Fig. 14 Temperature dependences of $\chi_{\mathrm{M}}{ }^{\prime}$ and $\chi_{\mathrm{M}}{ }^{\prime \prime}$ measured at $1 \mathrm{~Hz}$ (black), $10 \mathrm{~Hz}$ (light gray), $100 \mathrm{~Hz}$ (mid gray), and $1,000 \mathrm{~Hz}$ (dark gray) for $\left[\mathrm{Dy}(\mathrm{tta})_{3} \mathbf{L}^{\mathbf{1 0}}\right.$ ]$_{2}$ in the absence of an external dc field. Full symbols correspond to $\chi_{\mathrm{M}}{ }^{\prime}$ and empty symbols to $\chi_{\mathrm{M}}{ }^{\prime \prime}$

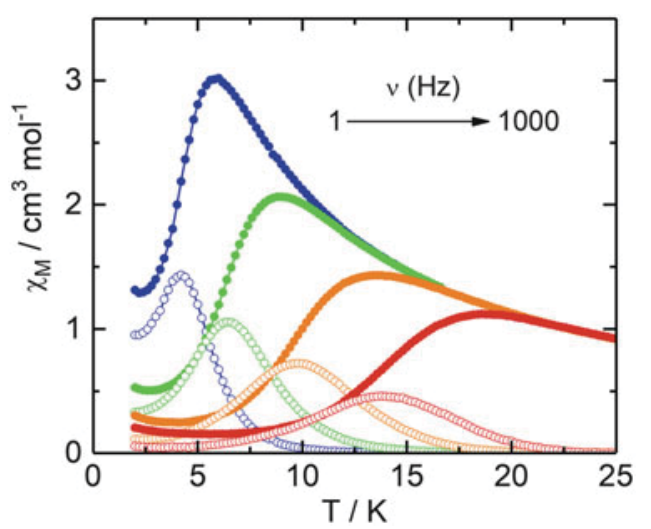


Fig. 15 (Top) field dependence of the relaxation time $\tau$ at $5 \mathrm{~K}$ with the magnetic field evolution of the energy levels in an Ising pattern for $\left[\mathrm{Dy}(\mathrm{tta})_{3} \mathbf{L}^{\mathbf{1 0}}\right]_{2}$. (Bottom) hysteresis loop for $\left[\text { Dy }(\mathrm{tta})_{3} \mathbf{L}^{\mathbf{1 0}}\right]_{2}$ measured at $1.5 \mathrm{~K}$ at a sweep rate of $66 \mathrm{Oe} \mathrm{s}^{-1}$
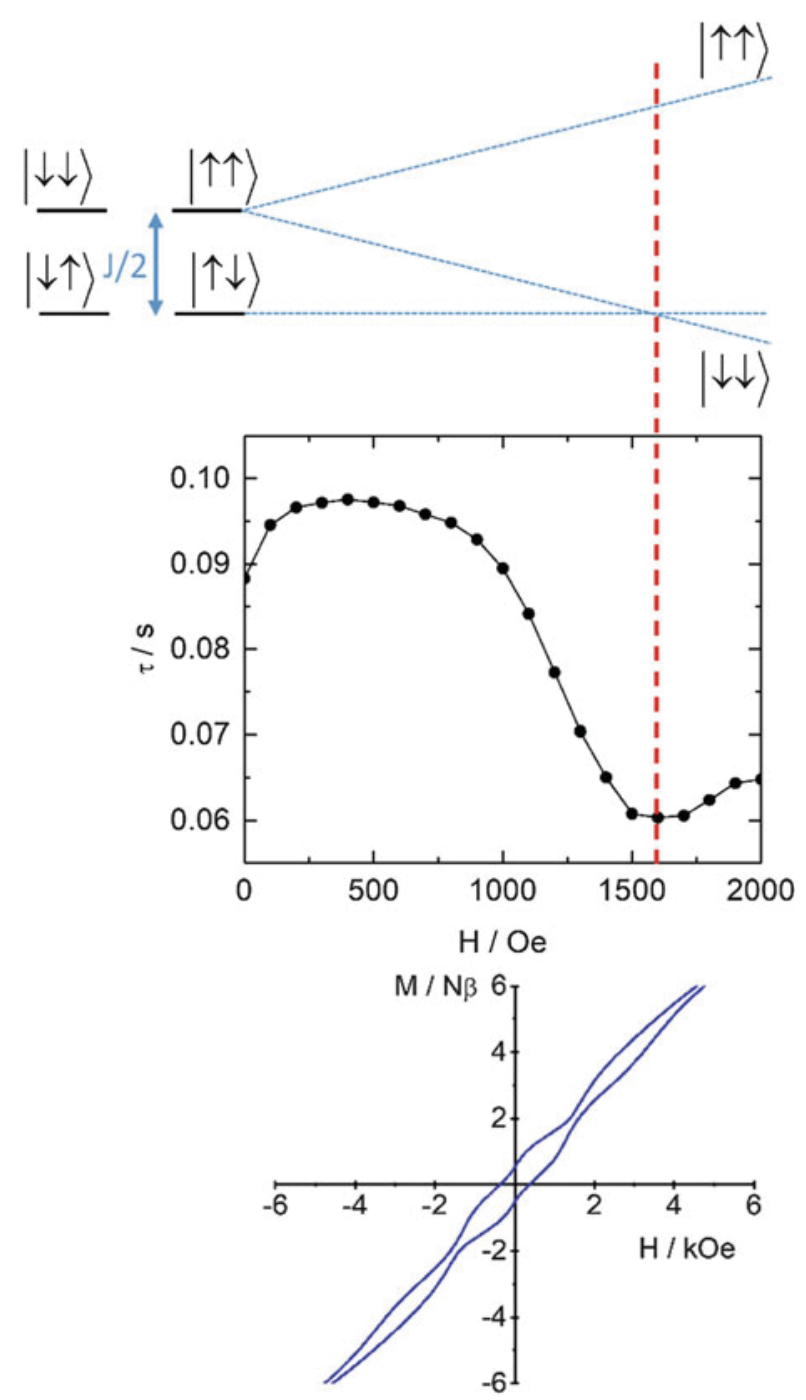

has also a consequence on the magnetic hysteresis. At $1.5 \mathrm{~K}$, the magnetic hysteresis 486 loop measured at $66 \mathrm{Oe} \mathrm{s}^{-1}$ differs significantly from those of mononuclear species 487 (Fig. 15) [71]. The butterfly transforms into a double butterfly. The neck at $1.3 \mathrm{kOe} 488$ traduces the acceleration of the relaxation at crossing field. In addition, the loop is 489 opened at the origin. One may say that this nonmagnetic object possesses a magnetic 490 memory anyway.

$\left[\mathrm{Dy}(\mathrm{hfac})_{2}\left(\mathrm{SO}_{3} \mathrm{CF}_{3}\right) \mathbf{L}^{\mathbf{1 1 \cdot +}}\right]_{2}$ is another example of dinuclear TTF-Ln-based com- 492 plexes [27] with 4,5-bis(3-pyridyl-N-oxidemethylthio)-4',5'-methyldithio- 493 tetrathiafulvene ligand $\left(\mathbf{L}^{\mathbf{1 1}}\right)$. This complex has some common points with [Dy 494 (tta) $\left.{ }_{3} \mathbf{L}^{\mathbf{1 0}}\right]_{2}$ : the coordination polyhedron is made of eight oxygen atoms, and 495 
496 pyridine $N$-oxide bridges two Dy(III) ions. However, in this system, one 497 monoanionic $\beta$-diketonate moiety has been substituted by one monoanionic sulfo498 nate. One oxygen atom from pyridine $N$-oxide group completes the coordination 499 sphere. The ligand $\mathbf{L}^{\mathbf{1 1}}$ has been oxidized during galvanostatic. The TTF core is 500 almost planar in agreement with its radical cationic form $\mathbf{L}^{\mathbf{1 1 \cdot +}}$. Two 501 non-coordinated sulfonate anions balance the positive charge of the complex. In 502 the crystal lattice, the TTF cores are dimerized with short intermolecular S $\cdots \mathrm{S}$ 503 contacts $(\sim 3.35 \AA)$, and then the radicals are magnetically inactive (strongly antifer504 romagnetically coupled). This is confirmed by the very weak EPR signal centered at $505 \mathrm{~g} \sim 2.007$ measured at $77 \mathrm{~K}$. The electrical resistivity measured at room temperature 506 on single crystals corresponds to an insulator. The analysis of the static magnetic 507 properties reveals a weak antiferromagnetic coupling $\left(J=-3 \times 10^{-3} \mathrm{~cm}^{-1}\right.$ 508 according to Eq. 1) and a Kramers ground state mainly constituted of $M_{J}= \pm 13 /$ 509 2. The $\chi_{\mathrm{M}}{ }^{\prime \prime}$ vs. $v$ curves at zero field does not pass through the characteristic 510 maximum at low temperature, so even if it is clear that $\left[\mathrm{Dy}(\mathrm{hfac})_{2}\left(\mathrm{SO}_{3} \mathrm{CF}_{3}\right) \mathbf{L}^{\mathbf{1 1}{ }^{\bullet+}}\right]_{2}$ 511 behaves as a SMM, it is less efficient than the previous example probably because 512 the environment around the lanthanide is chemically different.

513 The last two examples we would like to tackle are polynuclear complexes

514 which feature more than two metal centers. The rational design of a lanthanide515 based complex featuring different lanthanide motifs can be safely envisaged in 516 combining $\left[\mathrm{Dy}(\mathrm{tta})_{3} \mathbf{L}^{\mathbf{1 0}}\right]_{2}$ and $\left[\mathrm{Dy}(\mathrm{tta})_{3} \mathbf{L}^{\mathbf{2}}\right]$. To do so a TTF-based ligand has 517 been designed to feature a bridging site of pyridine $N$-oxide type and a 518 bischelating nitrogen-based site [72]. The ligand 2-\{1-methylpyridine-N-oxide519 4,5-[4,5-bis(pro-pylthio)tetrathiafulvalenyl]-1H-benzimidazol-2-yl $\}$ pyridine $\quad\left(\mathbf{L}^{\mathbf{1 2}}\right)$ 520 was then treated with two equivalents of $\left[\mathrm{Dy}(\mathrm{tta})_{3}\right] \cdot 2 \mathrm{H}_{2} \mathrm{O}$ to give the complex $521\left[\mathrm{Dy}_{4}(\mathrm{tta})_{12}\left(\mathbf{L}^{\mathbf{1 2}}\right)_{2}\right]$ (Fig. 16). In the complex, the reader will recognize one moiety 522 similar to $\left[\mathrm{Dy}(\mathrm{tta})_{3} \mathbf{L}^{\mathbf{1 0}}\right]_{2}$ and two moieties similar to $\left[\mathrm{Dy}(\mathrm{tta})_{3} \mathbf{L}^{\mathbf{2}}\right]$. The distance 523 between these moieties (metal-metal) is above $10 \AA$, so there is no direct 524 interaction between these three distinct SMMs. The magnetism of this object 525 should coincide with the superposition of two different SMMs.

526 In zero external field, the $\chi_{\mathrm{M}}$ vS. $\nu$ curves at various temperatures between 2 and $52711 \mathrm{~K}$ clearly show two well-separated relaxations which can be confronted to the 528 measurements on the isolated species. The presence of a slow and a fast process at 529 low and high frequencies, respectively, matches almost perfectly with the isolated 530 species. The low-frequency side corresponds to the dinuclear part and the high 531 frequency to the mononuclear. It is also possible to analyze quantitatively the 532 thermal and the in-field behaviors with a combination of two extended Debye 533 models. At this stage our synthetic approach allowed us to conceive a complex 534 which contains two different SMMs which act differently in the temperature and 535 time scales. This rational design is very promising to elaborate multifunctional 536 complexes (Fig. 17).

537 The last example we would like to comment concerns the polymeric species. [Yb 538 (hfac) $\left.)_{3}\right] \cdot 2 \mathrm{H}_{2} \mathrm{O}$ was reacted with the disodium salt of $\mathbf{L}^{\mathbf{1 3}}$ with $\mathbf{H}_{\mathbf{2}} \mathbf{L}^{\mathbf{1 3}}=4,5$-bis 539 (carboxylic)- $4^{\prime}, 5^{\prime}$-methyldithiotetrathiafulvene in dimethylformamide (DMF) to 540 produce $\left\{\left[\mathrm{YbL}^{\mathbf{1 3}}\left(\mathrm{H}_{2} \mathrm{O}\right)_{3}(\mathrm{DMF})\right] \cdot\left(\mathbf{H L}^{\mathbf{1 3}}\right) \cdot\left(\mathrm{H}_{2} \mathrm{O}\right)\right\}_{\mathrm{n}} \quad[73]$. The monodimensional 


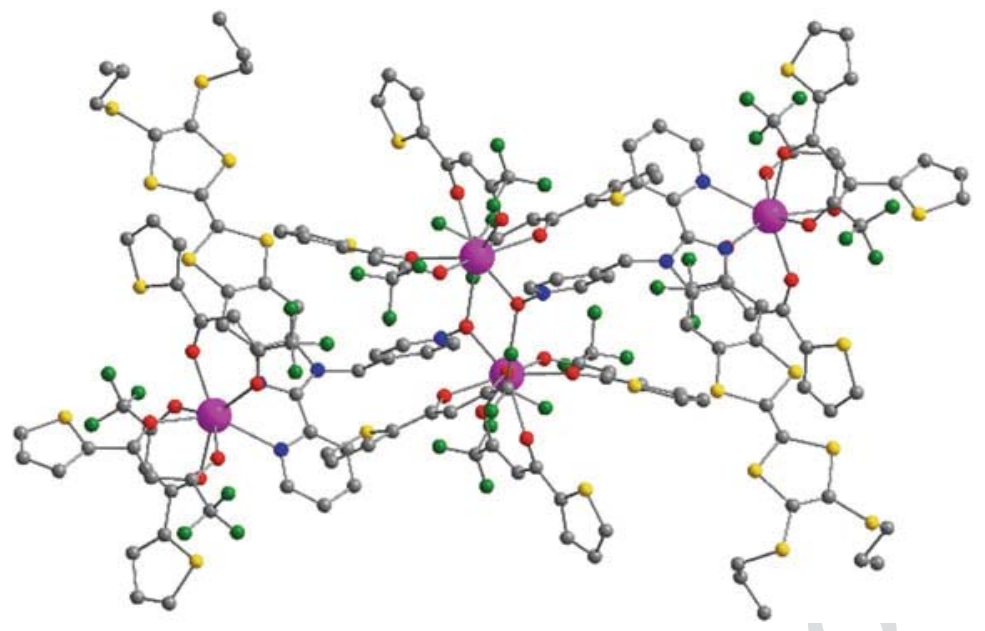

Fig. 16 Single-crystal X-ray structure of the tetranuclear complex $\left[\mathrm{Dy}_{4}(\mathrm{tta})_{12}\left(\mathbf{L}^{\mathbf{1 2}}\right)_{2}\right]$

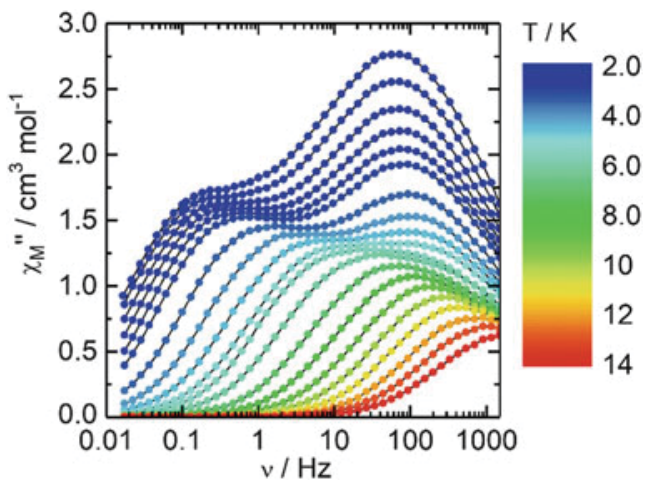

Fig. 17 Temperature and frequency dependence of the out-of-phase component of the ac susceptibility $\left[\mathrm{Dy}_{4}(\mathrm{tta})_{12} \mathbf{L}^{\mathbf{1 2}}{ }_{2}\right]$ measured in zero external dc field

polymer consists of chain of $\mathrm{Yb}(\mathrm{III})$ bridged by carboxylate anions in a $\mu_{2}\left(\eta_{1}, \eta_{1}\right) 541$ mode (Fig. 18). Coordination compounds of lanthanide ions with TTF-based ligands 542 are not so common and are essentially 0D. This is the first example of coordination 543 polymer of lanthanide with TTF-based ligand. The coordination polyhedron is made 544 of eight oxygen atoms in a $\mathrm{D}_{4 \mathrm{~d}}$ environment $\left(\mathrm{CShM}_{\mathrm{SAPR}-8}=0.454\right)$. Our efforts to 545 produce the dysprosium derivative were unsuccessful. It must be mentioned that no 546 $\mathrm{hfac}^{-}$anions are present in the structure and that the polymer cannot be obtained 547 from nitrate or halogenate salts of $\mathrm{Yb}(\mathrm{III})$. The system crystallizes in the triclinic 548 space group $P \overline{1}$ with one $\mathrm{Yb}(\mathrm{III})$ site, so the $g$-tensor can be extracted from single- 549 crystal rotating magnetometry. In the effective spin-1/25 model, $g_{x}=3.24,550$ $g_{y}=1.53$, and $g_{z}=4.25$. These values are far away from the Ising limit for which 551 
Fig. 18 Representation of the one-dimensional structure. The counterion $\left(\mathbf{H L}^{\mathbf{1 3}}\right)^{-}$has not been represented

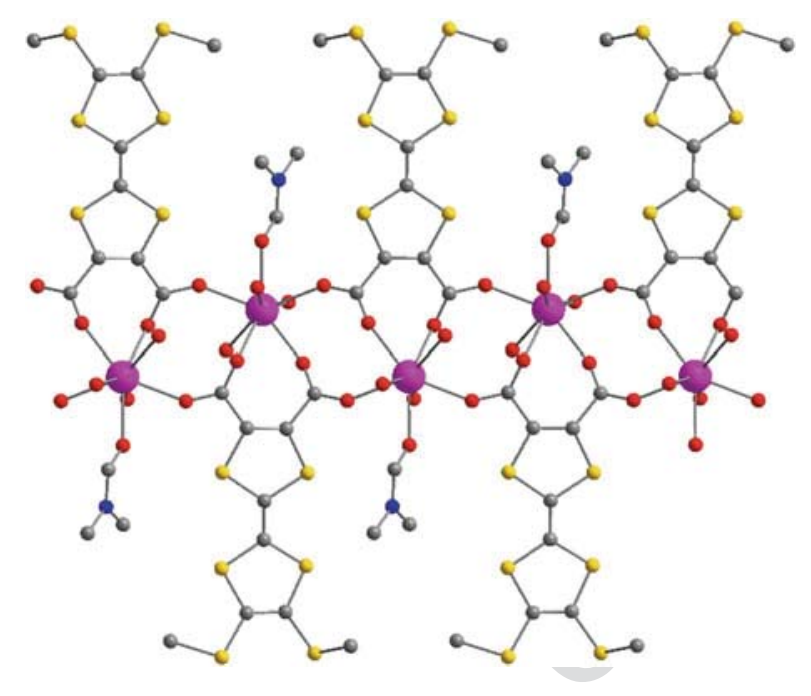

$552 g_{x}=g_{y}=0$ and $g_{z}=8.00$. As a result, the polymer does not behave as a SMM in 553 zero external dc field. Only when an external dc field is applied that $\chi_{\mathrm{M}}{ }^{\prime \prime}$ shows up. $g_{z}$ 554 orientation almost coincides with the fourfold axis of the square antiprism. We 555 tentatively tried to reproduce the static magnetic properties using the ab initio $556 \mathrm{CASSCF} / \mathrm{PT} 2 / \mathrm{SI}-\mathrm{SO}$ approach. Unfortunately, all tentative efforts failed to properly reproduce the magnetic susceptibility and magnetization curves. This underlines the difficulties already observed in the literature to efficiently model both the wave function and the energy of the low-lying multiplets of $\mathrm{Yb}(\mathrm{III})$ complexes.

\section{Conclusions}

561 In this chapter we wish to have convinced the reader that TTF-based ligands can be 562 employed to produce SMMs. We have focused the first part of this chapter on 563 strategies to enhance the magnetic performance of Dy-based SMM in a $\mathrm{N}_{2} \mathrm{O}_{6}$ 564 environment. A simple molecular engineering consisting in the modulation of the 565 electron withdrawing strength of the $\beta$-diketonate ancillary ligand highlighted the 566 importance of the electron charge density carried by the first neighboring atom to 567 control the energy crystal splitting and well isolate the ground multiplet state. The 568 canceling of the intermolecular (hydrogen bond and dipolar) interactions, thanks to 569 magnetic dilutions and spin-free isotopic enrichment, showed their efficiency to 570 decrease the quantum tunneling of the magnetization and therefore optimize the 571 magnetic properties of the SMM. Then the influence of the nature of the coordination 572 sphere was studied by the analysis of mononuclear SMM library in which the Dy(III) 573 is in $\mathrm{N}_{2} \mathrm{O}_{6}, \mathrm{~N}_{3} \mathrm{O}_{6}, \mathrm{O}_{8}$, and $\mathrm{O}_{9}$ environments. When the Dy(III) is placed in a $\mathrm{N}_{2} \mathrm{O}_{6}$ 574 environment, the Ising character of the magnetic anisotropy is enhanced compared to 
the $\mathrm{N}_{3} \mathrm{O}_{6}$ environment. In a general manner, SMM behavior is detected when the 575 negative charge is localized along an axis and in a plan, respectively, for the Dy(III) 576 and $\mathrm{Yb}(\mathrm{III})$ ions [41]. In a second part, we have increased the nuclearity of the 577 complexes. The role of the intramolecular magnetic interactions on the slow mag- 578 netic relaxation has been demonstrated.

Finally it is worth to notice that a large panel of theoretical and experimental tools 580 is available and can be used to reach a high level of understanding of the lanthanide 581 SMM magnetic properties, i.e., experimental measurements of the angular depen- 582 dence of the magnetization, correlation between magnetism and experimental lumi- 583 nescence, crystal-field determination by Stevens method, and ab initio calculations. 584

\section{References}

1. Sessoli R, Gatteschi D, Caneschi A, Novak MA (1993) Magnetic bistability in a metal-ion 586 cluster. Nature 365:141-143 587

2. Ishikawa N, Sugita M, Ishikawa T, Koshihara S, Kaizu Y (2003) Lanthanide double-decker 588 complexes functioning as magnets at the single-molecular level. J Am Chem Soc 589 125:8694-8695

3. Guo F-S, Day BM, Chen Y-C, Tong M-L, Mansikkamäki A, Layfield RA (2017) A dysprosium 591 metallocene single-molecule magnet functioning at the axial limit. Angew Chem Int Ed 592 56:11445-11449 593

4. Goodwin CAP, Ortu F, Reta D, Chilton NF, Mills DP (2017) Molecular magnetic hysteresis at 594 60 kelvin in dysprosocenium. Nature 548:439-442 595

5. Kobayashi H, Kobayashi A, Cassoux P (2000) BETS as a source of molecular magnetic 596 superconductors (BETS $=$ bis(ethylenedithio)tetraselenafulvalene). Chem Soc Rev 29:325-333 597

6. Coronado E, Galán-Mascarós JR, Gómez-García CJ, Laukhin V (2000) Coexistence of ferro- 598 magnetism and metallic conductivity in a molecule-based layered compound. Nature 599 408:447-449 600

7. Yamada J, Sugimoto T (2004) TTF chemistry: fundamentals and applications of 601 tetrathiafulvalene. Kodansha, Tokyo, Springer, Berlin 602

8. Bendikov M, Wudl F, Perepichka DF (2004) Tetrathiafulvalenes, oligoacenenes, and their 603 buckminsterfullerene derivatives: the brick and mortar of organic electronics. Chem Rev 604 104:4891-4946 605

9. Gorgues A, Hudhomme P, Sallé M (2004) Highly functionalized tetrathiafulvalenes: riding 606 along the synthetic trail from electrophilic alkynes. Chem Rev 104:5151-5184 607

10. Lorcy D, Bellec N, Fourmigué M, Avarvari N (2009) Tetrathiafulvalene-based group XV 608 ligands: Synthesis, coordination chemistry and radical cation salts. Coord Chem Rev 609 253:1398-1438 610

11. Pointillart F, Golhen S, Cador O, Ouahab L (2013) Paramagnetic 3d coordination complexes 611 involving redox-active tetrathiafulvalene derivatives: an efficient approach to elaborate multi- 612 properties materials. Dalton Trans 42:1949-1960 613

12. Gavrilenko KS, Gal YL, Cador O, Golhen S, Ouahab L (2007) First trinuclear paramagnetic 614 transition metal complexes with redox active ligands derived from TTF: $\mathrm{Co}_{2} \mathrm{M} 615$ $(\mathrm{PhCOO})_{6}(\mathrm{TTF}-\mathrm{CHCH}-\mathrm{py})_{2} \cdot 2 \mathrm{CH}_{3} \mathrm{CN}, \mathrm{M}=\mathrm{Co}^{\mathrm{II}}, \mathrm{Mn}{ }^{\mathrm{II}}$. Chem Commun 280-282 616

13. Benbellat N, Gavrilenko KS, Le Gal Y, Cador O, Golhen S, Gouasmia A, Fabre J-M, Ouahab L 617 (2006) $\mathrm{Co}(\mathrm{II})-\mathrm{Co}$ (II) paddlewheel complex with a redox-active ligand derived from TTF. Inorg 618 Chem 45:10440-10442 
14. Kolotilov SV, Cador O, Pointillart F, Golhen S, Le Gal Y, Gavrilenko KS, Ouahab L (2010) A new approach towards ferromagnetic conducting materials based on TTF-containing polynuclear complexes. J Mater Chem 20:9505-9514

15. Liu S-X, Ambrus C, Dolder S, Neels A, Decurtins S (2006) A dinuclear Ni(II) complex with two types of intramolecular magnetic couplings: $\mathrm{Ni}(\mathrm{II})-\mathrm{Ni}(\mathrm{II})$ and $\mathrm{Ni}(\mathrm{II})-\mathrm{TTF} \bullet+$. Inorg Chem 45:9622-9624

16. Cui L, Geng Y-F, Leong CF, Ma Q, D’Alessandro DM, Deng K, Zeng Q-D, Zuo J-L (2016) Synthesis, properties and surface self-assembly of a pentanuclear cluster based on the new $\pi$-conjugated TTF-triazole ligand. Sci Rep 6:srep25544

17. Mitsumoto K, Nishikawa H, Newton GN, Oshio H (2012) Encapsulation controlled single molecule magnetism in tetrathiafulvalene-capped cyanide-bridged cubes. Dalton Trans 41:13601-13608

18. Faulkner S, Burton-Pye BP, Khan T, Martin LR, Wray SD, Skabara PJ (2002) Interaction between tetrathiafulvalene carboxylic acid and ytterbium DO3A: solution state self-assembly of a ternary complex which is luminescent in the near IR. Chem Commun 1668-1669

19. Cui H, Otsuka T, Kobayashi A, Takeda N, Ishikawa M, Misaki Y, Kobayashi H (2003) Structural, electrical, and magnetic properties of a series of molecular conductors based on BDT-TTP and lanthanoid nitrate complex anions (BDT-TTP = 2,5-bis(1,3-dithiol-2-ylidene)1,3,4,6-tetrathiapentalene). Inorg Chem 42:6114-6122

20. Pointillart F, Le Gal Y, Golhen S, Cador O, Ouahab L (2009) 4f Gadolinium(III) complex involving tetrathiafulvalene-amido-2-pyrimidine-1-oxide as a ligand. Inorg Chem 48:4631-4633

21. Gao F, Cui L, Liu W, Hu L, Zhong Y-W, Li Y-Z, Zuo J-L (2013) Seven-coordinate lanthanide sandwich-type complexes with a tetrathiafulvalene-fused Schiff base ligand. Inorg Chem 52:11164-11172

22. Gao F, Zhang X-M, Cui L, Deng K, Zeng Q-D, Zuo J-L (2014) Tetrathiafulvalene-supported triple-decker phthalocyaninato dysprosium(III) complex: synthesis, properties and surface assembly. Sci Rep 4:srep05928

23. Ran Y-F, Steinmann M, Sigrist M, Liu S-X, Hauser J, Decurtins S (2012) Tetrathiafulvalenebased lanthanide coordination complexes: synthesis, crystal structure, optical and electrochemical characterization. Comptes Rendus Chim 15:838-844

24. Ueki S, Nogami T, Ishida T, Tamura M (2006) ET and TTF salts with lanthanide complex ions showing frequency-dependent ac magnetic susceptibility. Mol Cryst Liq Cryst 455:129-134

25. Pointillart F, le Guennic B, Cador O, Maury O, Ouahab L (2015) Lanthanide ion and tetrathiafulvalene-based ligand as a "magic" couple toward luminescence, single molecule magnets, and magnetostructural correlations. Acc Chem Res 48:2834-2842

26. D'Aleo A, Pointillart F, Ouahab L, Andraud C, Maury O (2012) Charge transfer excited states sensitization of lanthanide emitting from the visible to the near-infra-red. Coord Chem Rev 256:1604-1620

27. Pointillart F, Guennic BL, Golhen S, Cador O, Ouahab L (2013) Slow magnetic relaxation in radical cation tetrathiafulvalene-based lanthanide(III) dinuclear complexes. Chem Commun 49:11632-11634

28. Uzelmeier CE, Smucker BW, Reinheimer EW, Shatruk M, O’Neal AW, Fourmigué M, Dunbar KR (2006) A series of complexes of the phosphorus-based TTF ligand o-P2 with the metal ions $\mathrm{Fe}^{\mathrm{II}}, \mathrm{Co}^{\mathrm{II}}, \mathrm{Ni}^{\mathrm{II}}, \mathrm{Pd}^{\mathrm{II}}, \mathrm{Pt}^{\mathrm{II}}$, and $\mathrm{Ag}^{\mathrm{I}}$. Dalton Trans 5259-5268

29. Xiong J, Li G-N, Sun L, Li Y-Z, Zuo J-L, You X-Z (2011) Mono- and dinuclear Co/Ni complexes bearing redox-active tetrathiafulvaleneacetylacetonate ligands - syntheses, crystal structures, and properties. Eur J Inorg Chem 5173-5181

30. Guo YN, Xu GF, Gamez P, Zhao L, Lin SY, Deng R, Tang J, Zhang HJ (2010) Two-step relaxation in a linear tetranuclear dysprosium (III) aggregate showing single-molecule magnet behavior. J Am Chem Soc 132:8538-8539 
Tetrathiafulvalene-Based Magnets of Lanthanides

31. Guo YN, Xu GF, Wernsdorfer W, Ungur L, Guo Y, Tang J, Zhang HJ, Chibotaru LF, Powell 671 AK (2011) Strong axiality and Ising exchange interaction suppress zero-field tunneling of 672 magnetization of an asymmetric Dy2 single-molecule magnet. J Am Chem Soc 673 133:11948-11951 674

32. Lin S-Y, Wernsdorfer W, Ungur L, Powell AK, Guo Y-N, Tang J, Zhao L, Chibotaru LF, 675 Zhang H-J (2012) Coupling Dy3 triangles to maximize the toroidal moment. Angew Chem Int 676 Ed 51:12767-12771 677

33. Guo Y-N, Ungur L, Granroth GE, Powell AK, Wu C, Nagler SE, Tang J, Chibotaru LF, Cui D 678 (2014) An NCN-pincer ligand dysprosium single-ion magnet showing magnetic relaxation via 679 the second excited state. Sci Rep 4:5471 680

34. Layfield RA (2014) Organometallic single-molecule magnets. Organometallics 33:1084-1099 681

35. Guo Y-N, Xu G-F, Guo Y, Tang J (2011) Relaxation dynamics of dysprosium(III) single 682 molecule magnets. Dalton Trans 40:9953-9963 683

36. Zhang P, Zhang L, Tang J (2015) Lanthanide single molecule magnets: progress and perspec- 684 tive. Dalton Trans 44:3923-3929 685

37. Ungur L, Lin S-Y, Tang J, Chibotaru LF (2014) Single-molecule toroics in Ising-type lantha- 686 nide molecular clusters. Chem Soc Rev 43:6894-6905 687

38. Pointillart F, Cador O, Le Guennic B, Ouahab L (2017) Uncommon lanthanide ions in purely $4 \mathrm{f} 688$ single molecule magnets. Coord Chem Rev 346:150-175 689

39. Pointillart F, Le Gal Y, Golhen S, Cador O, Ouahab L (2011) Single-molecule magnet 690 behaviour in a tetrathiafulvalene-based electroactive antiferromagnetically coupled dinuclear 691 dysprosium(III) complex. Chem Eur J 17:10397-10404 692

40. Llunell M, casanova D, Cicera J, Bofill JM, Alemany P, Alvarez S (2013) SHAPE (version 2.1) 693

41. Rinehart JD, Long JR (2011) Exploiting single-ion anisotropy in the design of f-element single- 694 molecule magnets. Chem Sci 2:2078-2085 695

42. Sievers J (1982) Asphericity of 4f-shells in their Hund's rule ground states. Z Für Phys B 696 Condens Matter 45:289-296 697

43. Ungur L, Chibotaru LF (2011) Magnetic anisotropy in the excited states of low symmetry 698 lanthanide complexes. Phys Chem Chem Phys 13:20086-20090 699

44. Ungur L, Chibotaru LF (2016) Strategies toward high-temperature lanthanide-based single- 700 molecule magnets. Inorg Chem 55:10043-10056 701

45. Cosquer G, Pointillart F, Golhen S, Cador O, Ouahab L (2013) Slow magnetic relaxation in 702 condensed versus dispersed dysprosium(III) mononuclear complexes. Chem Eur J 703 19:7895-7903 704

46. Jung J, Cador O, Bernot K, Pointillart F, Luzon J, Le Guennic B (2014) Influence of the 705 supramolecular architecture on the magnetic properties of a DyIII single-molecule magnet: an 706 ab initio investigation. Beilstein J Nanotechnol 5:2267-2274 707

47. da Cunha TT, Jung J, Boulon M-E et al (2013) Magnetic poles determinations and robustness of 708 memory effect upon solubilization in a DyIII-based single ion magnet. J Am Chem Soc 709 135:16332-16335 $\quad 710$

48. Orbach R (1961) Spin-lattice relaxation in rare-earth salts. Proc R Soc Lond A 264:458-484 711

49. Pointillart F, Bernot K, Golhen S, Le Guennic B, Guizouarn T, Ouahab L, Cador O (2015) 712 Magnetic memory in an isotopically enriched and magnetically isolated mononuclear dyspro- 713 sium complex. Angew Chem Int Ed 54:1504-1507 714

50. Gatteschi D, Sessoli R (2003) Quantum tunneling of magnetization and related phenomena in 715 molecular materials. Angew Chem Int Ed 42:268-297 716

51. Ishikawa N, Sugita M, Wernsdorfer W (2005) Nuclear spin driven quantum tunneling of 717 magnetization in a new lanthanide single-molecule magnet: bis(phthalocyaninato)holmium 718 anion. J Am Chem Soc 127:3650-3651 719

52. Ishikawa N, Sugita M, Wernsdorfer W (2005) Quantum tunneling of magnetization in lantha- 720 nide single-molecule magnets: bis(phthalocyaninato)terbium and bis(phthalocyaninato)dyspro- 721 sium anions. Angew Chem Int Ed 44:2931-2935 
53. Flores Gonzales J, Pointillart F, Ouahab L, Cador O. Hyperfine coupling and slow magnetic relaxation in isotopically enriched Dy(III) mononuclear single-molecule magnets. Submitted

54. Ebenhöh W, Ehlers VJ, Ferch J (1967) Hyperfine-structure measurements on Dy ${ }^{161}$ and Dy ${ }^{163}$. Z Für Phys 200:84-92

55. Childs WJ (1970) Hyperfine structure of ${ }^{5} \mathrm{I}_{8,7}$ atomic states of $\mathrm{Dy}^{161,163}$ and the ground-state nuclear moments. Phys Rev A 2:1692-1701

56. Kishi Y, Pointillart F, Lefeuvre B, Riobé F, Guennic BL, Golhen S, Cador O, Maury O, Fujiwara H, Ouahab L (2017) Isotopically enriched polymorphs of dysprosium single molecule magnets. Chem Commun 53:3575-3578

57. Fujiwara H, Yokota S, Hayashi S, Takemoto S, Matsuzaka H (2010) Development of photofunctional materials using TTF derivatives containing a 1,3-benzothiazole ring. Phys B Condens Matter 405:S15-S18

58. Speed S, Feng M, Garcia GF et al (2017) Lanthanide complexes involving multichelating TTF-based ligands. Inorg Chem Front 4:604-617

59. Cole KS, Cole RH (1941) Dispersion and absorption in dielectrics I. Alternating current characteristics. J Chem Phys 9:341-351

60. Abragam A, Bleaney B (2012) Electron paramagnetic resonance of transition ions.Reprint edn. Oxford University Press, Oxford

61. Feng M, Pointillart F, Lefeuvre B, Dorcet V, Golhen S, Cador O, Ouahab L (2015) Multiple single-molecule magnet behaviors in dysprosium dinuclear complexes involving a multiple functionalized tetrathiafulvalene-based ligand. Inorg Chem 54:4021-4028

62. Jia C, Liu S-X, Tanner C, Leiggener C, Neels A, Sanguinet L, Levillain E, Leutwyler S, Hauser A, Decurtins S (2007) An experimental and computational study on intramolecular charge transfer: a tetrathiafulvalene-fused dipyridophenazine molecule. Chem Eur J 13:3804-3812

63. Pointillart F, Jung J, Berraud-Pache R et al (2015) Luminescence and single-molecule magnet behavior in lanthanide complexes involving a tetrathiafulvalene-fused dipyridophenazine ligand. Inorg Chem 54:5384-5397

64. Kuropatov V, Klementieva S, Fukin G, Mitin A, Ketkov S, Budnikova Y, Cherkasov V, Abakumov G (2010) Novel method for the synthesis of functionalized tetrathiafulvalenes, an acceptor-donor-acceptor molecule comprising of two o-quinone moieties linked by a TTF bridge. Tetrahedron 66:7605-7611

65. Pointillart F, Klementieva S, Kuropatov V, Gal YL, Golhen S, Cador O, Cherkasov V, Ouahab L (2012) A single molecule magnet behaviour in a D3h symmetry Dy(III) complex involving a quinone-tetrathiafulvalene-quinone bridge. Chem Commun 48:714-716

66. Soussi K, Jung J, Pointillart F, Guennic BL, Lefeuvre B, Golhen S, Cador O, Guyot Y, Maury O, Ouahab L (2015) Magnetic and photo-physical investigations into Dy(III) and Yb (III) complexes involving tetrathiafulvalene ligand. Inorg Chem Front 2:1105-1117

67. Huang G, Fernandez-Garcia G, Badiane I et al. Magnetic slow relaxation in a metal organic framework made of chains of ferromagnetically coupled single-molecule magnets. Chem Eur J. doi: https://doi.org/10.1002/chem.201800095

68. Zhang P, Jung J, Zhang L, Tang J, Le Guennic B (2016) Elucidating the magnetic anisotropy and relaxation dynamics of low-coordinate lanthanide compounds. Inorg Chem 55:1905-1911

69. Pointillart F, Guennic BL, Golhen S, Cador O, Maury O, Ouahab L (2013) A redox-active luminescent ytterbium based single molecule magnet. Chem Commun 49:615-617

70. Pointillart F, Golhen S, Cador O, Ouahab L Slow magnetic relaxation in a redox-active tetrathiafulvalene-based ferromagnetic dysprosium complex. Eur J Inorg Chem 2014, 2014:4558-4563

71. Pointillart F, Le Guennic B, Maury O, Golhen S, Cador O, Ouahab L (2013) Lanthanide dinuclear complexes involving tetrathiafulvalene-3-pyridine-N-oxide ligand: semiconductor radical salt, magnetic, and photophysical studies. Inorg Chem 52:1398-1408 
Tetrathiafulvalene-Based Magnets of Lanthanides

72. Pointillart F, Guizouarn T, Lefeuvre B, Golhen S, Cador O, Ouahab L (2015) Rational design of 774 a lanthanide-based complex featuring different single-molecule magnets. Chem Eur J 775 21:16929-16934

73. Belio Castro A, Jung J, Golhen S, Le Guennic B, Ouahab L, Cador O, Pointillart F (2016) Slow 777 magnetic relaxation in unprecedented mono-dimensional coordination polymer of ytterbium 778 involving tetrathiafulvalene-dicarboxylate linker. Magnetochemistry 2:26 